\title{
Factors that Influence the Performance of Elite Sprint Cross-Country Skiers
}

\author{
Kim Hébert-Losier ${ }^{1,2} \cdot$ Christoph Zinner $^{2,3} \cdot$ Simon Platt $^{2} \cdot$ Thomas Stöggl $^{2,4}$ • \\ Hans-Christer Holmberg ${ }^{2}$
}

Published online: 22 June 2016

(c) The Author(s) 2016. This article is published with open access at Springerlink.com

\begin{abstract}
Background Sprint events in cross-country skiing are unique not only with respect to their length $(0.8-1.8 \mathrm{~km})$, but also in involving four high-intensity heats of $\sim 3 \mathrm{~min}$ in duration, separated by a relatively short recovery period (15-60 min).

Objective Our aim was to systematically review the scientific literature to identify factors related to the performance of elite sprint cross-country skiers.

Methods Four electronic databases were searched using relevant medical subject headings and keywords, as were reference lists, relevant journals, and key authors in the field. Only original research articles addressing physiology, biomechanics, anthropometry, or neuromuscular characteristics and elite sprint cross-country skiers and performance outcomes were included. All articles meeting inclusion criteria were quality assessed. Data were extracted from each article using a standardized form and subsequently summarized.

Results Thirty-one articles met the criteria for inclusion, were reviewed, and scored an average of $66 \pm 7 \%$ (range 56-78 \%) upon quality assessment. All articles except for
\end{abstract}

Kim Hébert-Losier

hl.kim@isn.gov.my

1 Department of Sports Science, National Sports Institute of Malaysia, National Sports Complex, 57000 Bukit Jalil, Kuala Lumpur, Malaysia

2 Department of Health Sciences, Swedish Winter Sports Research Centre, Mid Sweden University, Östersund, Sweden

3 Department of Sport Science, Julius-Maximilians-University Würzburg, Würzburg, Germany

4 Department of Sport Science and Kinesiology, University of Salzburg, Salzburg, Austria two were quasi-experimental, and only one had a fullyexperimental research design. In total, articles comprised 567 subjects ( $74 \%$ male), with only nine articles explicitly reporting their skiers' sprint International Skiing Federation points (weighted mean $116 \pm 78$ ). A similar number of articles addressed skating and classical techniques, with more than half of the investigations involving roller-skiing assessments under laboratory conditions. A range of physiological, biomechanical, anthropometric, and neuromuscular characteristics was reported to relate to sprint skiing performance. Both aerobic and anaerobic capacities are important qualities, with the anaerobic system suggested to contribute more to the performance during the first of repeated heats; and the aerobic system during subsequent heats. A capacity for high speed in all the following instances is important for the performance of sprint cross-country skiers: at the start of the race, at any given point when required (e.g., when being challenged by a competitor), and in the final section of each heat. Although high skiing speed is suggested to rely primarily on high cycle rates, longer cycle lengths are commonly observed in faster skiers. In addition, faster skiers rely on different technical strategies when approaching peak speeds, employ more effective techniques, and use better coordinated movements to optimize generation of propulsive force from the resultant ski and pole forces. Strong uphill technique is critical to race performance since uphill segments are the most influential on race outcomes. A certain strength level is required, although more does not necessarily translate to superior sprint skiing performance, and sufficient strength-endurance capacities are also of importance to minimize the impact and accumulation of fatigue during repeated heats. Lastly, higher lean mass does appear to benefit sprint skiers' performance, with no clear advantage conferred via body height and mass. 
Limitations Generalization of findings from one study to the next is challenging considering the array of experimental tasks, variables defining performance, fundamental differences between skiing techniques, and evolution of sprint skiing competitions. Although laboratory-based measures can effectively assess on-snow skiing performance, conclusions drawn from roller-skiing investigations might not fully apply to on-snow skiing performance. A low number of subjects were females (only $17 \%$ ), warranting further studies to better understand this population. Lastly, more training studies involving high-level elite sprint skiers and investigations pertaining to the ability of skiers to maintain high-sprint speeds at the end of races are recommended to assist in understanding and improving high-level sprint skiing performance, and resilience to fatigue.

Conclusions Successful sprint cross-country skiing involves well-developed aerobic and anaerobic capacities, high speed abilities, effective biomechanical techniques, and the ability to develop high forces rapidly. A certain level of strength is required, particularly ski-specific strength, as well as the ability to withstand fatigue across the repeated heats of sprint races. Cross-country sprint skiing is demonstrably a demanding and complex sport, where high-performance skiers need to simultaneously address physiological, biomechanical, anthropometric, and neuromuscular aspects to ensure success.

\section{Key Points}

The structure of sprint cross-country skiing events is quite unique, as it involves four high-intensity heats (each $\sim 3$ min in duration) separated by a relatively short recovery period (15-60 $\mathrm{min})$.

Numerous physiological, biomechanical, anthropometric, and neuromuscular factors exert an impact on sprint skiing performance. The key factors that promote good performance include welldeveloped aerobic and anaerobic capacities, adequate strength and ski-specific power, a high proportion of lean mass, effective skiing biomechanics, and an ability to attain and maintain high speeds during a single heat, as well as a series of heats.

\section{Introduction}

Cross-country skiing has been contested at the Olympics since the first Winter Games held in Chamonix, France, in 1924. Since then, the sport of cross-country skiing has evolved to include two distinct styles (skating and classic) and a range of race distances (from sprint to long distance events of $800 \mathrm{~m}$ to $50 \mathrm{~km}$ in length). The Dolomitensprint, featured in Lienz in 1979, is claimed to be the first sprint cross-country skiing race (http://www.dolomitensport.at). Sprint skate skiing races were first introduced officially into the World Cup in 1996 in Reit im Winkl and into World Championships contests in 2001 in Lahti. In 2005, sprint classic skiing sprints appeared in these contests in Otepää and Oberstdorf, respectively (Fig. 1). Sprint events became officially part of the Winter Games for the first time in Salt Lake City in 2002. The most recent 2014 Winter Games in Sochi involved a total of 12 cross-country skiing events (six for men and six for women), of which four were sprint races.

Over the years, several reviews have summarized the evidence relating to the biomechanics $[1,2]$, physiology $[3,4]$, and injuries [5, 6] associated with cross-country skiing. However, these reviews do not encompass the scientific literature relating to sprint events. Recently, Sandbakk and Holmberg [7] provided a short invited commentary on factors leading to success in Olympic cross-country skiing in which select similarities and differences between long distance and sprint skiers were highlighted. A number of skiers are able to compete successfully in both distance and sprint events [8]. For example, Marit Bjørgen (Norway) finished first overall in both the distance and sprint events for women during the 2014-2015 World Cup; and Petter Northug (Norway) finished first in both the $50-\mathrm{km}$ and individual-sprint events for men during the 2015 International Ski Federation (FIS) Nordic World Ski Championships. However, although some biomechanical and physiological factors are crucial for high-level performance in both short- and long-distance races, a more precise investigation of factors relating to sprint cross-country skiing performance is needed.

Sprint races are from 1.0 to $1.8 \mathrm{~km}$ in length for men and from 0.8 to $1.6 \mathrm{~km}$ for women, and are contested in both classic and skating techniques. Sprint races are unique in cross-country skiing not only in terms of length, but also in terms of involving repeated heats. In contrast to most skiing events which have one mass start, sprint races begin with an individual prologue (i.e., time-trial qualification round) from which the 30 fastest skiers progress to knockout heats. Six athletes compete head-to-head in each heat, with the fastest two skiers from each heat (five heats $\times$ two skiers) progressing to the semi-finals along with the two other fastest skiers (lucky losers) who did not finish among the top two of their respective heats. A total of 12 skiers then compete in two semi-final heats comprised of six skiers each, with only six skiers making the finals. Hence, a skier must compete in an individual prologue, a quarterfinal, and a semi-final before reaching the final to have a 


\begin{tabular}{|c|c|c|c|c|c|c|c|}
\hline & $\perp$ & $\perp$ & 1 & $\perp$ & $\perp$ & $\perp$ & $\perp$ \\
\hline Year & 1979 & 1996 & 2001 & 2002 & 2005 & 2005 & 2010 \\
\hline Competition & Dolomitesprint & World Cup & World Championships & Winter Olympics & World Cup & World Championships & Winter Games \\
\hline Skiing style & - & Skating & Skating & Skating & Classic & Classic & Classic \\
\hline City & Lienz & Reit im Winkel & Lahtii & Salt Lake City & Otepää & Oberstdorf & Vancouver \\
\hline
\end{tabular}

Fig. 1 A brief history of sprint cross-country skiing

chance at medalling [9]. This structure makes sprint events quite different from the more traditional distance races, involving four high-intensity heats (each typically $\sim 3 \mathrm{~min}$ in duration) separated by a relatively short period of recovery (15-60 min).

At the elite level, sprint cross-country skiing events are extremely competitive. Improvements as small as $0.39 \%$ in sprint cross-country skiing race times have been proposed to represent worthwhile enhancements in prologue performance, which could improve an athlete's chance of securing a place on the winners' podium [10]. In parallel, a substantial body of research has emerged regarding sprint cross-country skiing performance over the last decade. For example, investigations have been conducted using a variety of methods, ranging from purely laboratory-based [11-13] to on snow [14, 15] and in competition [16, 17]. These studies have highlighted numerous factors underpinning sprint cross-country skiing performance, which broadly fall under physiology, biomechanics, anthropometry, and neuromuscular. Both aerobic [18] and anaerobic [11] capacities appear to be requisite for high-level performance in sprint skiing, together with the ability to generate high forces [12], select appropriate skiing techniques [15], and utilize optimal skiing biomechanics [12]. It is noteworthy that peak skiing speed has been correlated to performance during a simulated competition involving three 1,100-m heats [19], as well as to skiers' FIS-sprint points [18]. Given the small winning margins in elite sprint cross-country skiing, there is a need for an in-depth understanding of the factors influencing performance and a detailed appraisal of the literature relating to this particular sport.

In this context, the present systematic review aims to identify and summarize the physiological, biomechanical, anthropometric, and neuromuscular factors that relate to elite sprint cross-country skiing performance. This appraisal should provide an overview of pertinent factors to optimize performance of sprint skiers, as well as serve as a guide for future research in sprint cross-country skiing.

\section{Methods}

This systematic review of the literature adheres to the structure and reporting guidelines of PRISMA (Preferred Reporting Items for Systematic Reviews and Meta-Analyses) [20].

\subsection{Search Strategy}

The PubMed, SciVerse Scopus, SPORTDiscus ${ }^{\mathrm{TM}}$, and Web of Knowledge ${ }^{\text {SM }}$ databases were searched systematically on 29 March 2015, using "sprint ski OR sprint skiing OR sprint cross country" as the search strategy (Fig. 2). In addition, the reference lists of all articles thus identified and subsequently chosen for inclusion were searched manually for additional articles of relevance, as were publications by key researchers in this field (e.g., Hans-Christer Holmberg, Jussi Mikkola, Thomas Stöggl, Øyvind Sandbakk, and Raphael Zory) and the table of contents of relevant journals (e.g., the Scandinavian Journal of Medicine and Science in Sports, and the International Journal of Sports Physiology and Performance).

\subsection{Inclusion and Exclusion Criteria}

Only original research articles addressing biomechanics, physiology, anthropometry, or neuromuscular characteristics in combination with sprint cross-country skiing performance were included, whereas articles addressing equipment, environmental, or other external factors were excluded. More precisely, only original research studies that involved elite cross-country skiers (i.e., at least at the national level), assessed sprint skiing performance (either on snow or in the laboratory), related variables to sprint skiing performance, and were published in the English language in peer-reviewed journals were included. Articles that examined peak skiing speed were included only if of direct relevance to sprint skiers and sprint skiing performance at an elite level. Articles that addressed peak skiing speed without contextualization to sprint skiing or elite athletes were excluded. Articles on other types of skiing (e.g., biathlon, distance cross-country skiing, and alpine skiing) and letters to the editor, symposium reports, conference abstracts, special technical publications, books, expert opinions, commentaries, and literature reviews were excluded.

\subsection{Study Selection Process}

Duplicate articles identified electronically through the different databases searched were removed first. Next, to minimize bias, a third party eliminated any potentially 


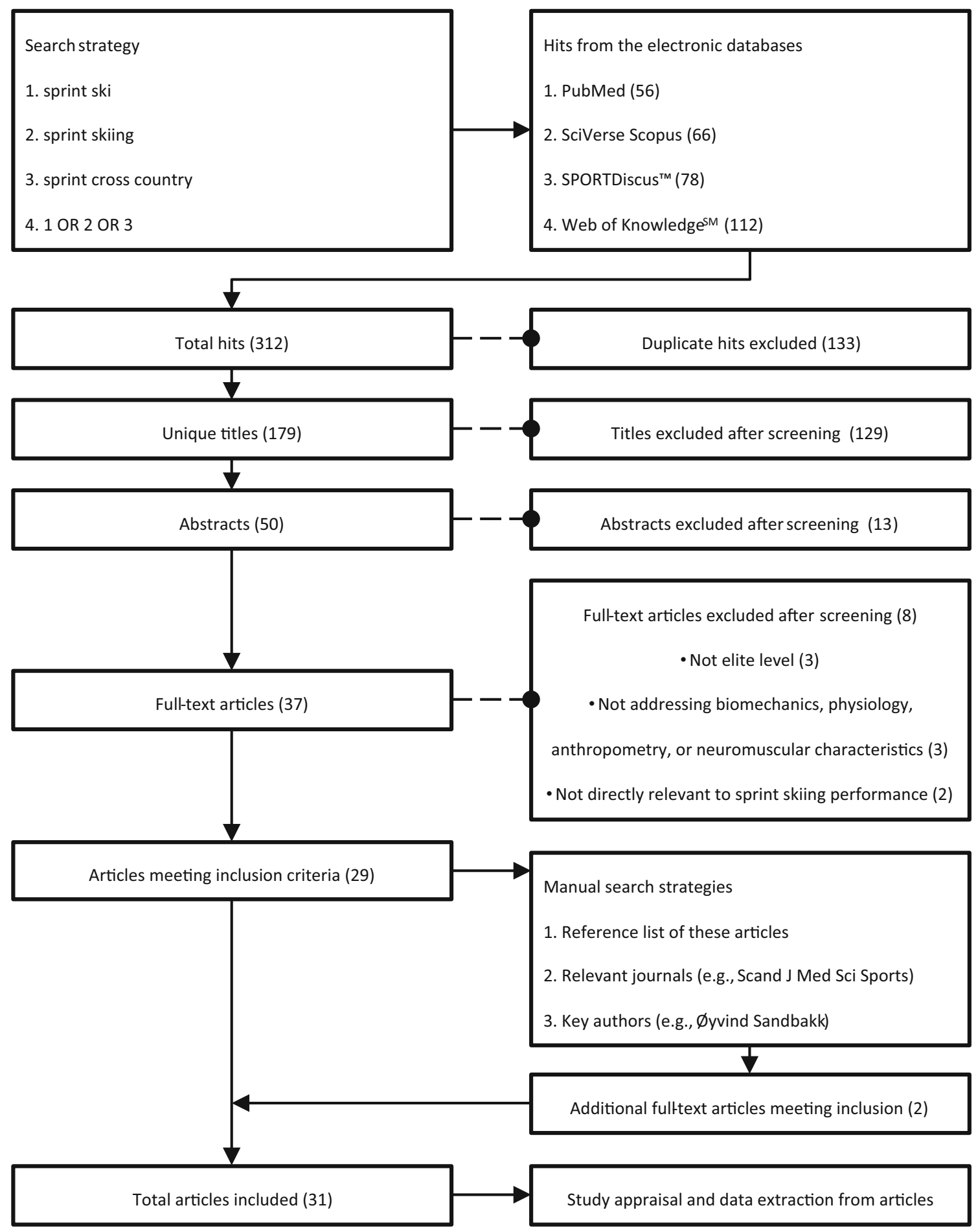

Fig. 2 Flow diagram of the search strategy and the article selection process

identifiable information (i.e., authors, names, affiliations, country of origin, and journal title). Thereafter, two independent reviewers (CZ and SP) screened all of the titles, abstracts, and full-texts in that order for inclusion and exclusion. Results from the two independent screenings were compared and, in case of disagreement, a third reviewer (KHL) was consulted to reconcile differences. The study selection process was repeated for articles identified through other searches until no additional publications of interest were found. 


\subsection{Study Appraisal}

To assess the quality of articles fulfilling the criteria for inclusion, we employed a modified version of the Downs and Black Quality Assessment Checklist [21], which provides an overall quality score for different study designs and is suitable for articles on elite sport performance [22, 23]. Furthermore, this checklist exhibits high internal consistency (Kuder-Richardson $20=0.89$ ), test-retest reliability $(r=0.88)$, inter-rater reliability $(r=0.75)$, and criterion validity in comparison to global scores from the Standards of Reporting Trials Group $(r=0.90)$ [21, 24].

Modifications made to the original checklist included replacing the words "patient" with "subject/participant", "interventions" with "conditions", and "treatment" with "testing". On questions 8, 9, 14, 15, 17, 19, 23, 24, and 26, "Not applicable" was added as a fourth scoring option. Question 27 was scored "Yes" (1 point-statistical significance attained), "No" (0 point-no statistical significance), or "Not applicable" (no statistical analyses performed). When an article reported or provided a reference to the accuracy of a measurement system, question 20 was scored "Yes".

In questions 5 and 25, FIS points, age, and sex were considered to be core confounders; while body mass, specialization (i.e., sprint or distance skiing), country of origin, and years of experience were considered to be other confounders. To receive two points on question 5, all three core confounders and at least one other confounder had to be reported. For one point, three confounders, including at least two core confounders had to be recorded. Otherwise, a score of zero was given. After excluding questions scored as "Not applicable", the final score was calculated as a percentage: [(total number of points/total number of applicable points) $\times 100 \%$ ], where a higher percentage score indicates a study of superior quality.

Since the quality score did not depend on study design, standard classification schemes $[25,26]$ were employed to classify the design of each study, first as experimental, quasiexperimental, or non-experimental, and then as a case study, case series, or repeated-measures design. No article was excluded on the basis of its quality score or study design.

The same two investigators ( $\mathrm{CZ}$ and SP) who screened for inclusion criteria assessed the quality and classified the design of all articles independently. Again, a third reviewer (KHL) reconciled any disagreements, with any potentially identifying information still lacking at this stage from articles.

\subsection{Data Extraction, Synthesis, and Analysis}

Data concerning the study aims, population, location, methodologies, key results, and variables examined (as well as their relationships to the performance of elite sprint skiers) were extracted using a standardized form. Each reviewer $(\mathrm{CZ}$ and SP) independently extracted data from half of the articles allocated in a randomized fashion. These two reviewers subsequently exchanged articles and the data extracted to verify that the procedure was accurate and complete. The major skiing techniques addressed in the current review are
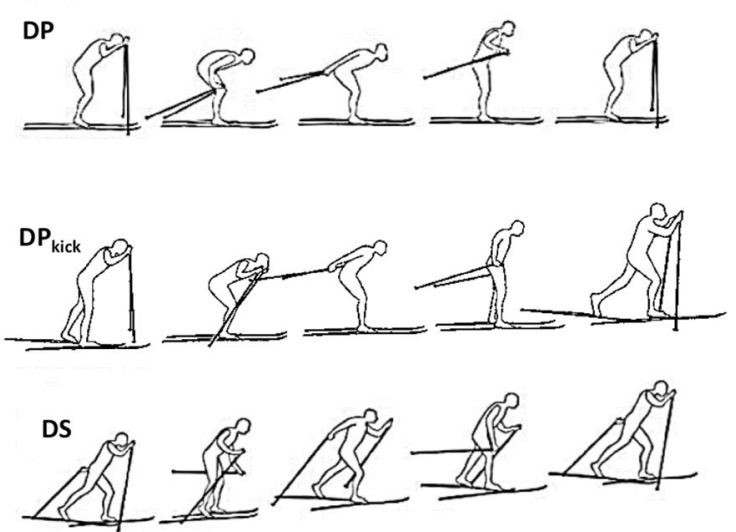

Classical techniques

Fig. 3 Schematic illustration of a subset of the major classical (left column) and skating (right column) techniques used in cross-country skiing. $D P$ double poling: mainly used on level to moderate uphill terrain. Poles are employed simultaneously with no leg push. $D P_{\text {kick }}$ kick double poling: mainly used on moderate uphill terrain. Poles are employed simultaneously with one leg push. DS diagonal stride: mainly used on moderate to steep uphill terrain. Arms and legs move in a diagonal fashion, with the poling action occurring with the
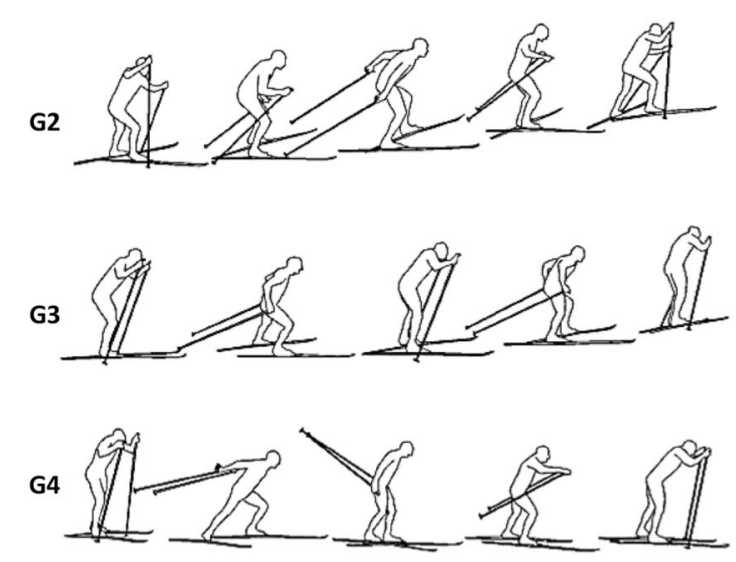

Skating techniques

contra-lateral leg push. G2 gear 2 (or V1 skate): mainly used on moderate to steep uphill terrain. Asymmetric poling action for every second leg push. G3 gear 3 (or V2 skate): mainly used on level to moderate uphill terrain. One symmetric poling action for each leg push. G4 gear 4 (or V2 alternate skate): mainly used on level terrain. One symmetric poling action for every second leg push. The doublepush skating technique (not illustrated) is a derivative of G3 and involves two pushes with the propulsive leg, rather than one 
illustrated in Fig. 3. Peak $\left(V \mathrm{O}_{2 \text { peak }}\right)$ and maximal $\left(V \mathrm{O}_{2 \max }\right)$ oxygen uptake reflect different theoretical and practical constructs [27]. However, given the inconsistent usage and interpretation of these terms in the articles reviewed here, the term $V \mathrm{O}_{2 \text { peak }}$ is used to encompass both. Similarly, the term peak velocity $\left(v_{\text {peak }}\right)$ is applied to encompass parameters referred to as "maximal" or "peak" velocity or speed in these articles. Readers should thus consult the original publications for further specification.

The data were analysed using Microsoft Excel ${ }^{\circledR} 2010$ (Microsoft Corporation, Redmont, WA, USA). The results were expressed using means and standard deviations (mean $\pm \mathrm{SD}$ ), minimum to maximum ranges, counts, and/ or percentages.

\section{Results}

The initial database search yielded 312 hits of which 179 remained after the removal of duplicates. After screening the titles, abstracts, and full-texts, 29 of these articles were found to fulfil the inclusion criteria. Two additional articles were identified through our supplementary searches (Fig. 2).

\subsection{Quality Score and Research Design}

The quality scores, research designs, subjects, primary variables of interest, and key findings of each article are presented in Table 1. The average quality score of the 31 articles was $66 \pm 7 \%$ (range 56-78) on the basis of our modified Downs and Black Quality Assessment Checklist. The main quality issues were failure to consider the representativeness of the study population, state the period during which the subjects were recruited, adjust for confounders, and report actual probability values (e.g., $p=0.035$ rather than $<0.05$ ). Of the 31 studies, 29 were classified as quasi-experimental with a case series design [11, 12, 14, 15, 17-19, 28-48], one as experimental [49], and one as non-experimental [16].

\subsection{Subjects and Experimental Protocols}

The mean number of subjects was $18 \pm 19$ (range 6-111), including altogether 567 subjects from eight different countries (Table 1). Most subjects (74\%) were male, $17 \%$ were female, and the sex of the remaining $9 \%$ involved in three articles $[16,32,36]$ was not specified. The mean age of subjects across studies (weighted by articles' sample size) was $24.6 \pm 2.7 \mathrm{y}$. Only nine articles explicitly reported the FIS-sprint points earned by their skiers, with a weighted mean of $116 \pm 78[13,17,18,29,37$, $40,43,47,50]$. As shown in Table 1 , not all subjects were sprint-skiing specialists.
Fifteen articles (48 \%) focused on the classic technique $[14,16,19,30,34-36,40,42-47,50], 11(35 \%)$ on the skating technique $[11,17,18,28,29,31,32,37,39$, $41,49]$, and the remaining five $(16 \%)$ involved both [12, 15, 33, 38, 48]. Seventeen studies (55\%) involved roller-skiing on a treadmill in the laboratory [11-13, 15, 17-19, 29, 30, 33, 37, 41-43, 45, 46, 49], and $12(39 \%)$ examined skiing performance on snow [14-17, 31, 32, 34-36, 40, 44, 47]. Only two of these studies $(6 \%)$ evaluated skiing in both of these environments [15, 17]. Other approaches and environments to assessing ski-specific skills involved ergometers [34-36, 43, 44, 46], tartan tracks [38, 39, 42, 46, 50], and paved roads [18, 42, 50].

Of the various experimental protocols employed to assess sprint cross-country skiing performance (see "Task" in Table 1), simulated races (i.e., time trial) involving either a single or repeated heats were chosen in numerous studies [14, 15, 17, 19, 34-39, 42-44, 46, 49] and actual races in two [16, 47]. Performance was heterogeneously defined across the literature, being based on a single heat time-trial [15, 17, 43, 49], a repeated heats time-trial $[19,34-36,38,39]$, peak skiing speed [12, 15, 30-33, 41, 45, 46], or level of expertise [18, 29, 48] (e.g., World Class skiers vs. national-level skiers and medallists vs. non-medallists). Only nine studies (29\%) examined the relationship between FIS-sprint points and experimental variables [15, 17, 18, 29, 37, 40, 43, 47, 50].

\subsection{Performance Factors}

A range of factors were found to influence or be related to elite sprint cross-country skiing performance (see "Key Results and Implications for Performance" in Table 1). In most cases, a combination of physiological and biomechanical aspects were evaluated (see "Focus" in Table 1), although 14 studies were considered to focus more on biomechanics [12, 14-17, 31-33, 36, 40, 41, 44-46], 13 on physiology $[11,13,18,19,29,37-39,42,43,48-50]$, two on anthropometrics [30,47], and two on neuromuscular characteristics [34, 35]. The key factors identified are summarized in Table 1, outlined here, and addressed in greater detail in Sect. 4.

With respect to physiology, aerobic $[17,18$, 38, 39, 48, 49] and anaerobic capacities [11, 19, 37-39], as well as skiing economy and efficiency [17, 18, 28, 29] were found to be major factors that distinguish sprint skiers with different levels of performance. Most findings indicate that aerobic capacity (i.e., $V \mathrm{O}_{2 \text { peak }}$ ) exerts a significant impact on performance during time-trials involving both a single and repeated heats [17, 29, 37, 38, 43, 49]. Vesterinen et al. [39] stressed the importance of aerobic characteristics in sprint cross-country skiing as well, showing that high level 


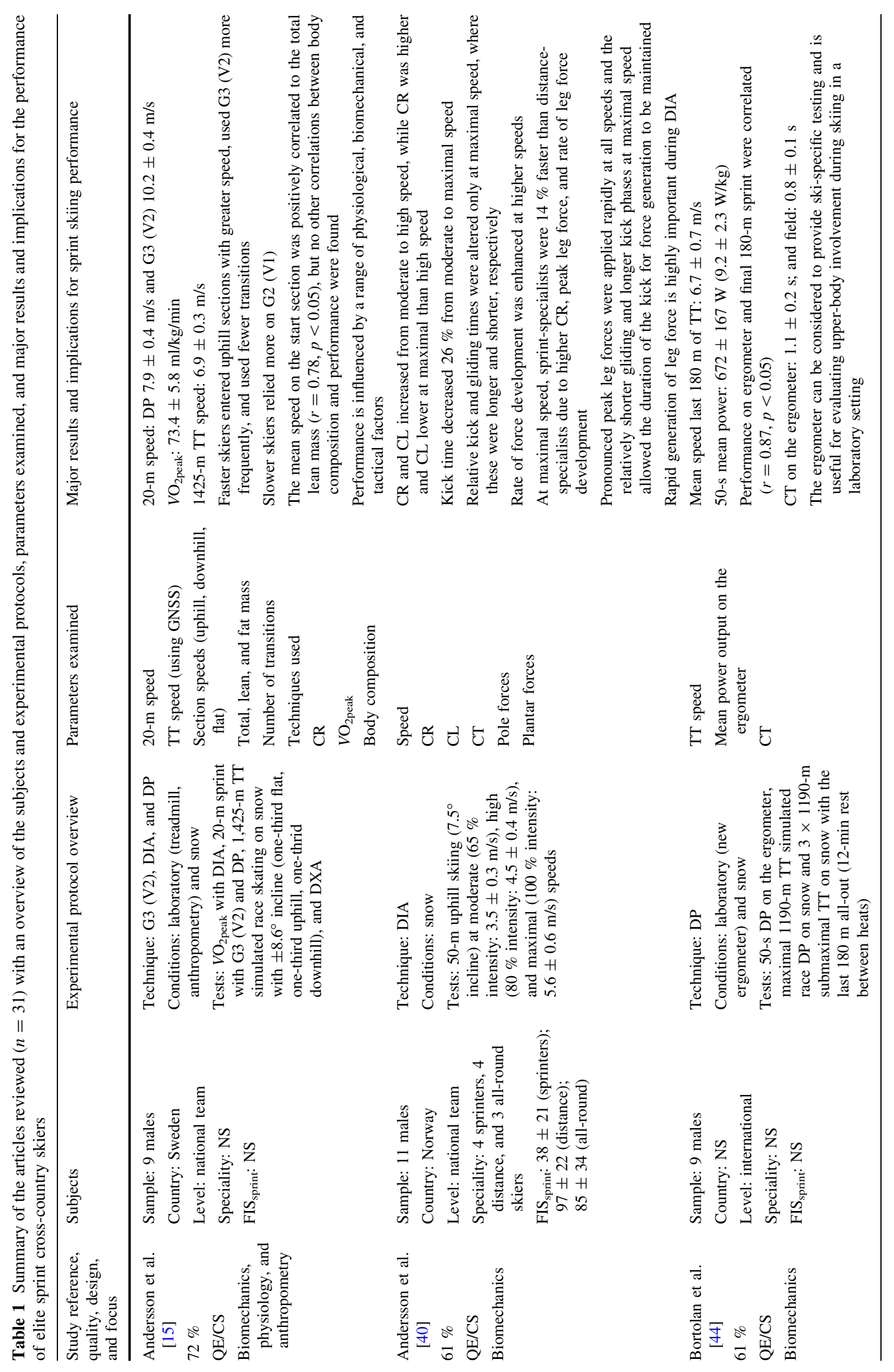




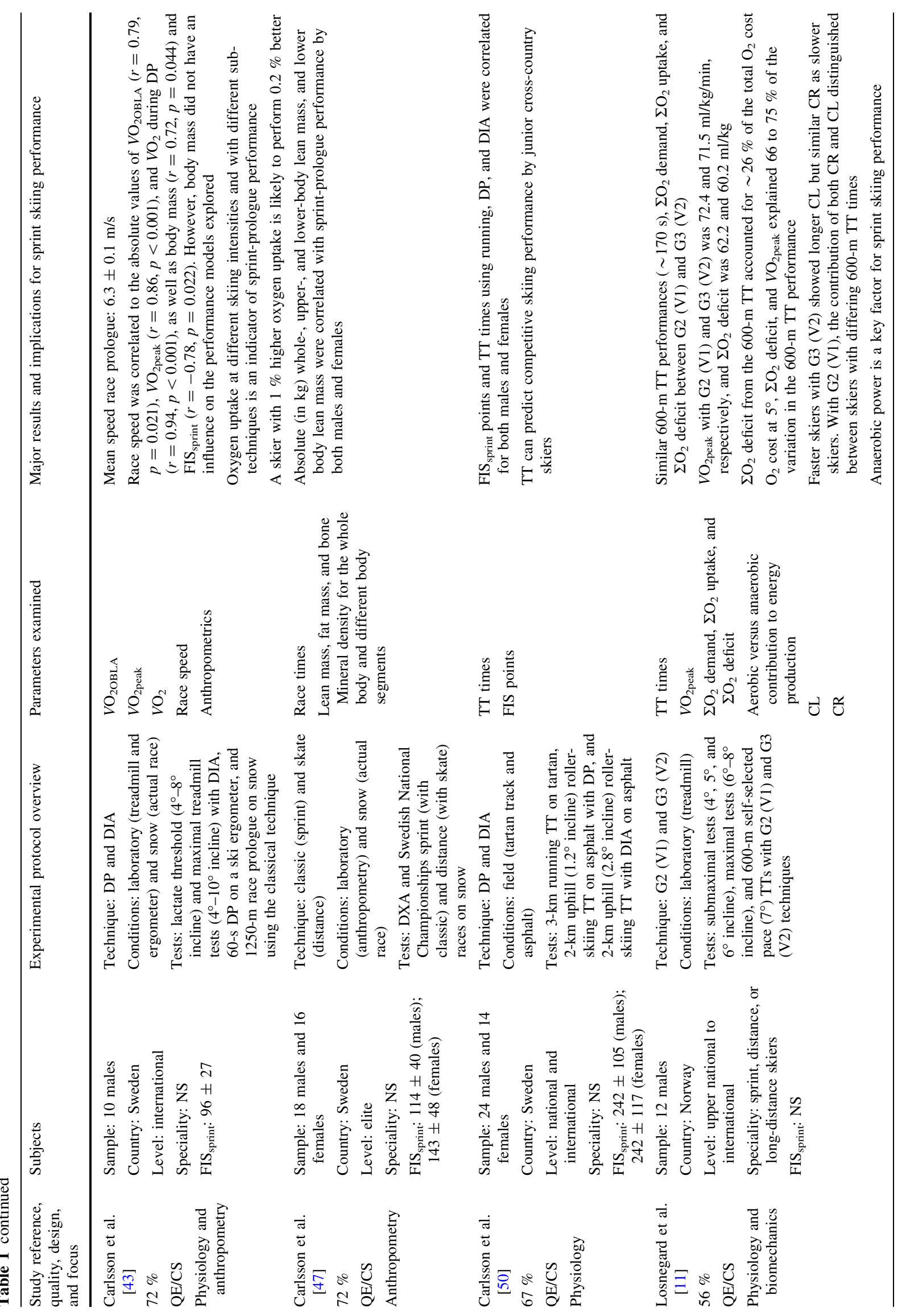




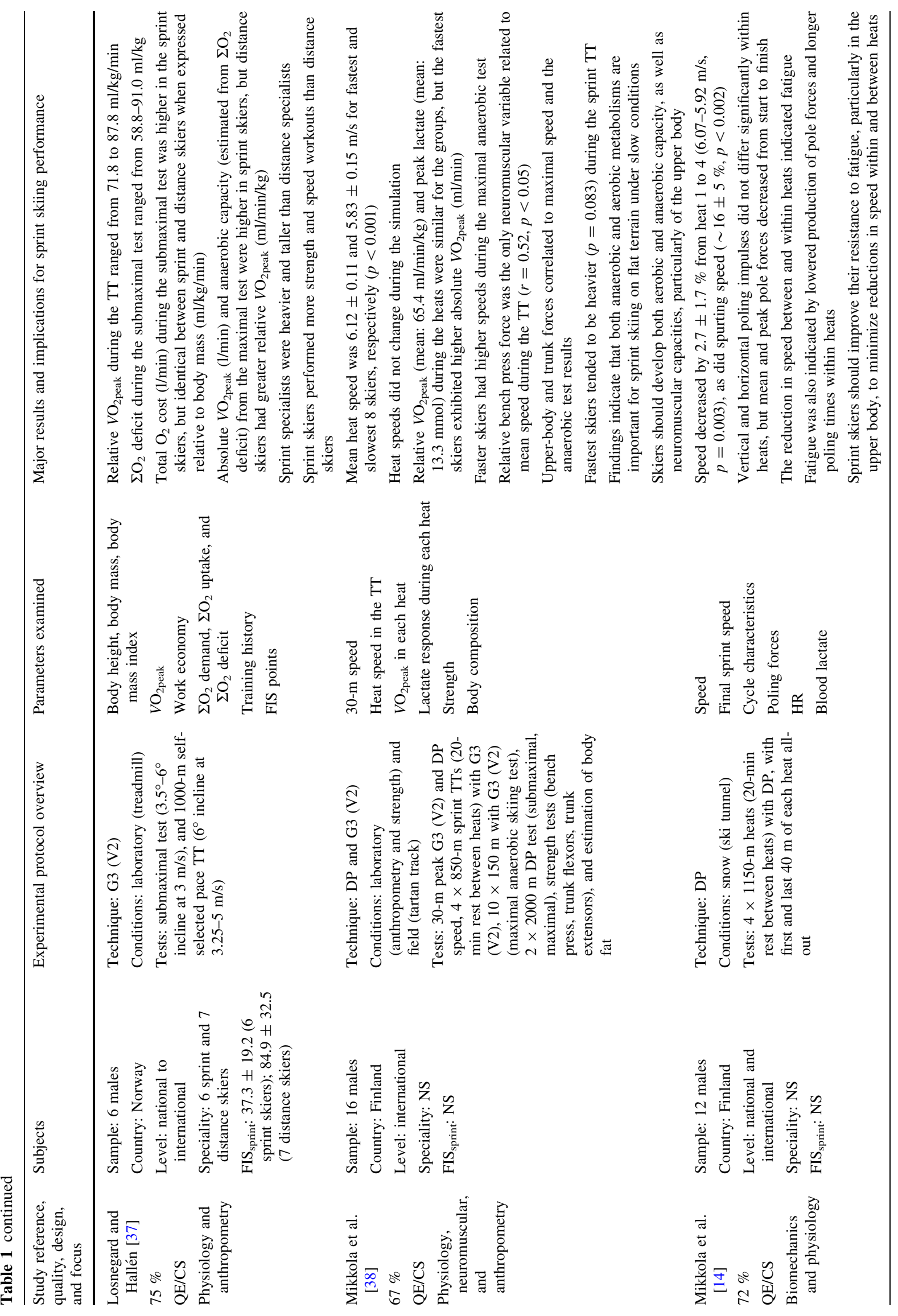




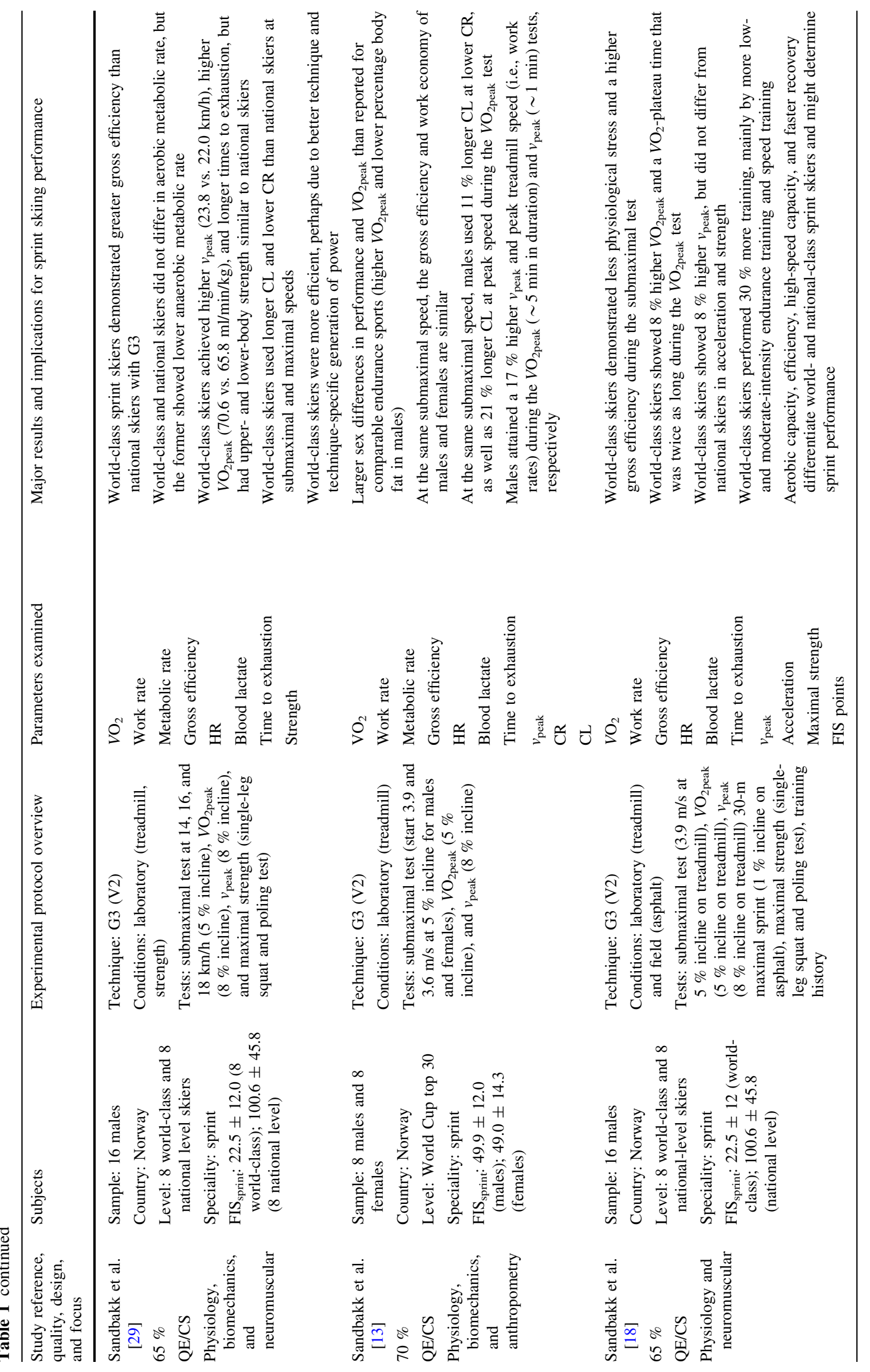




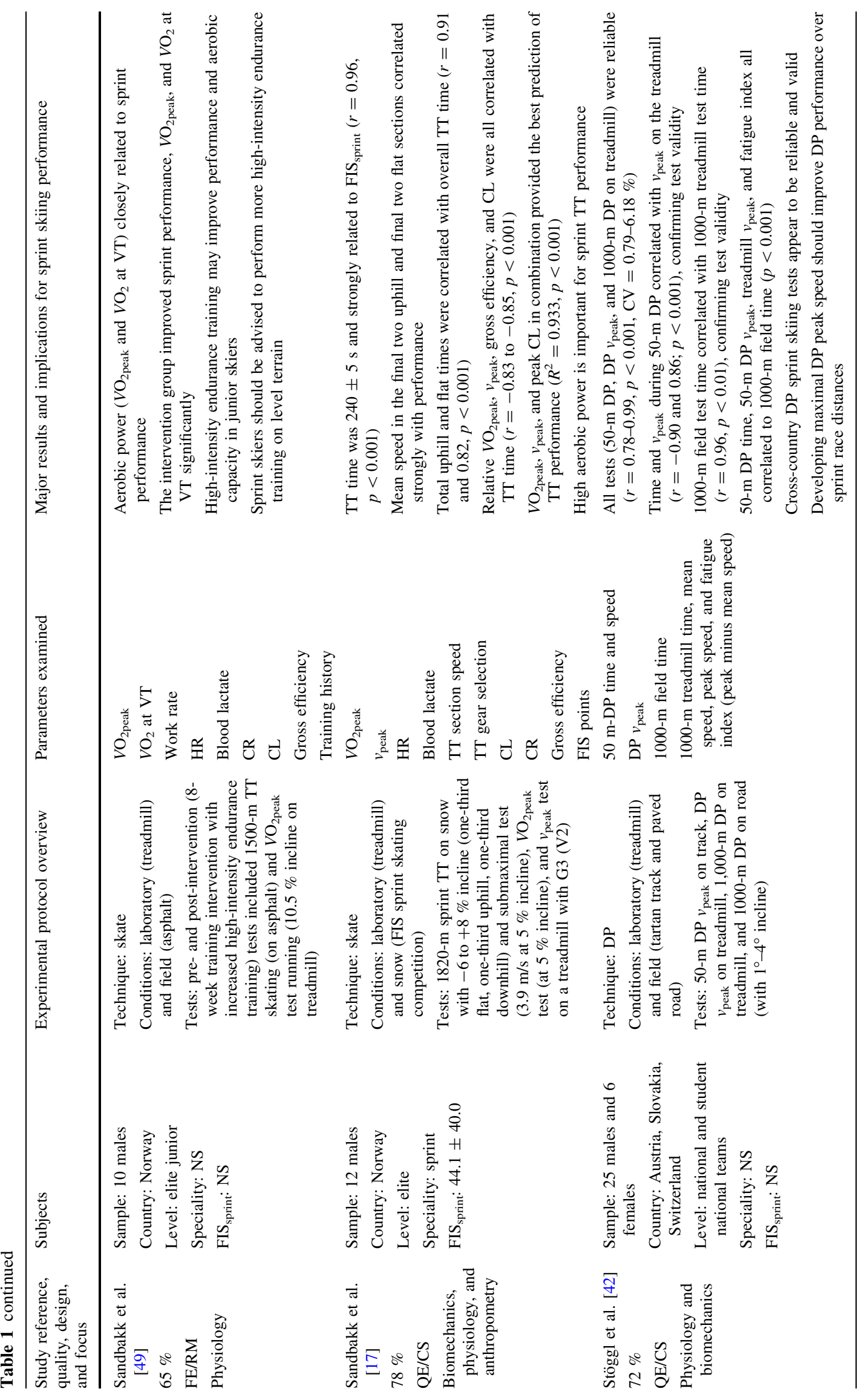




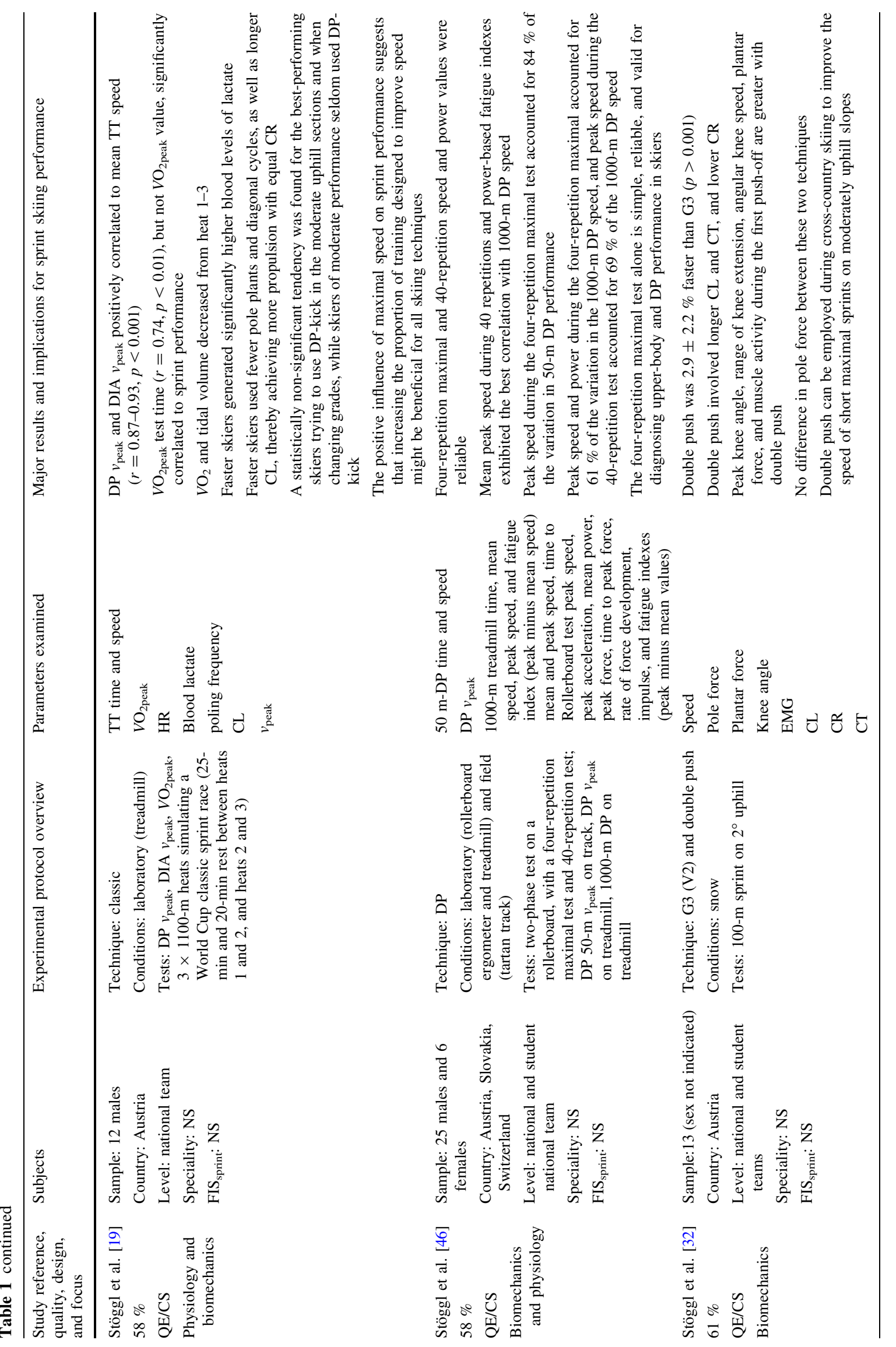




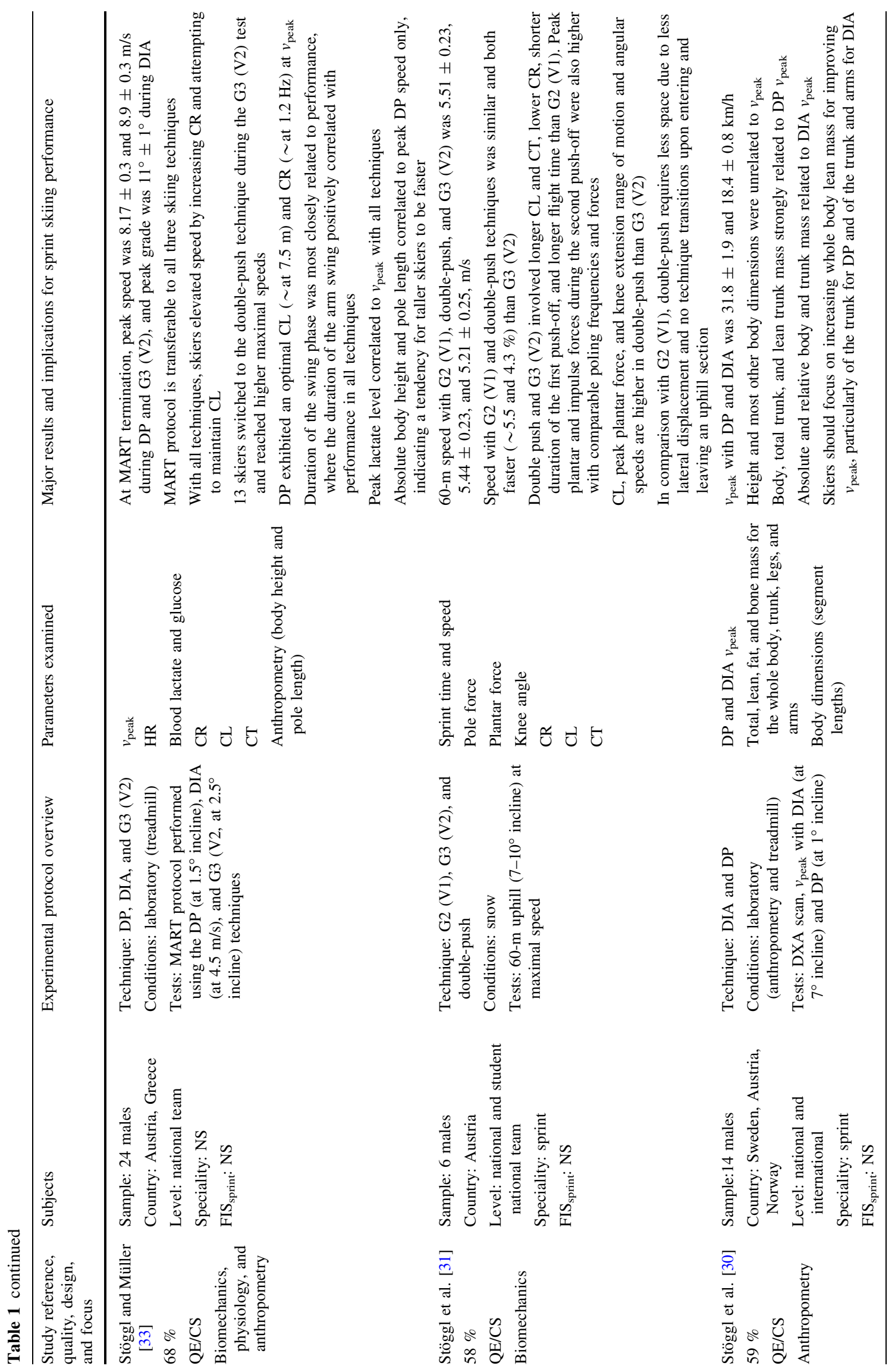




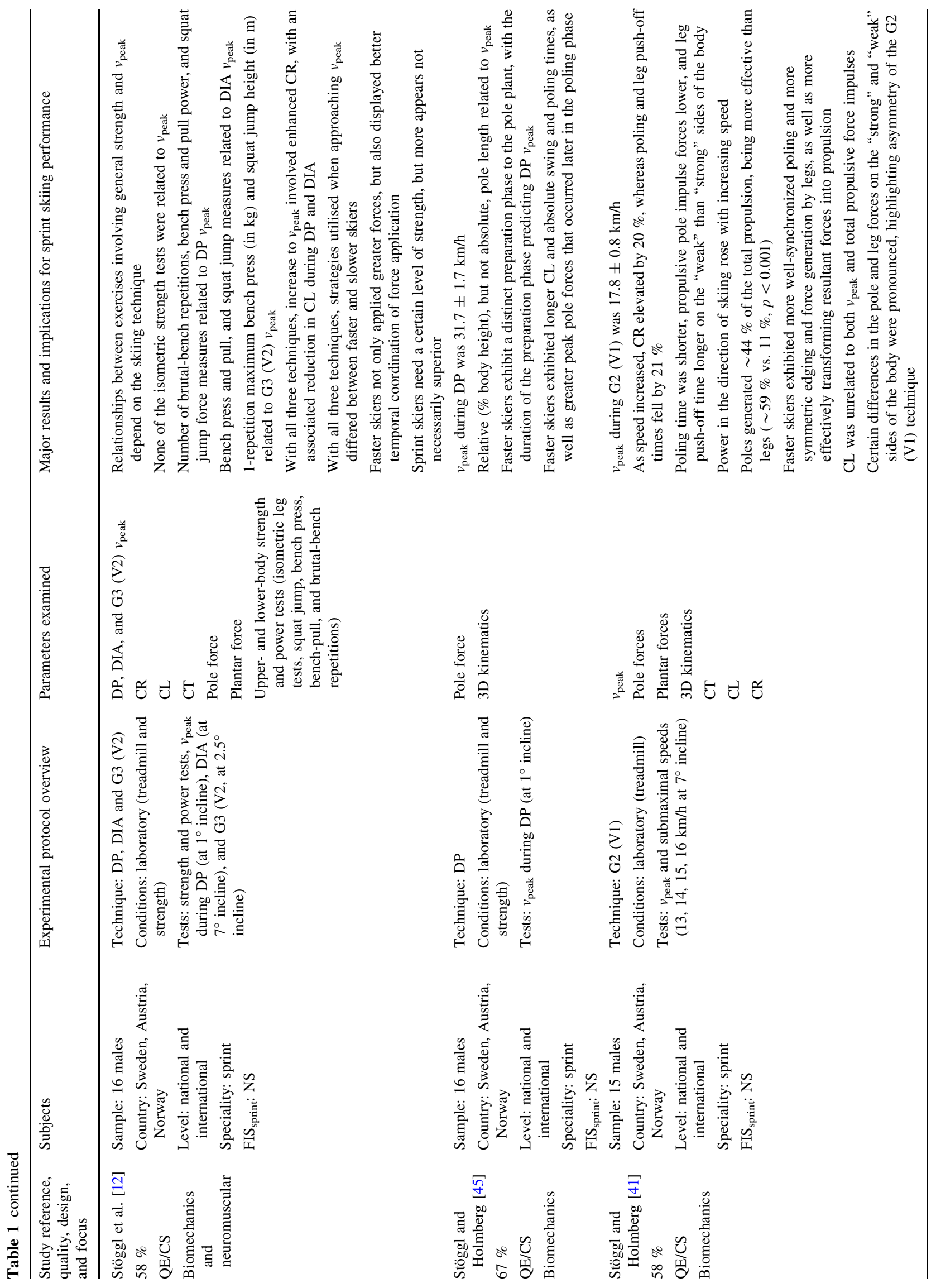




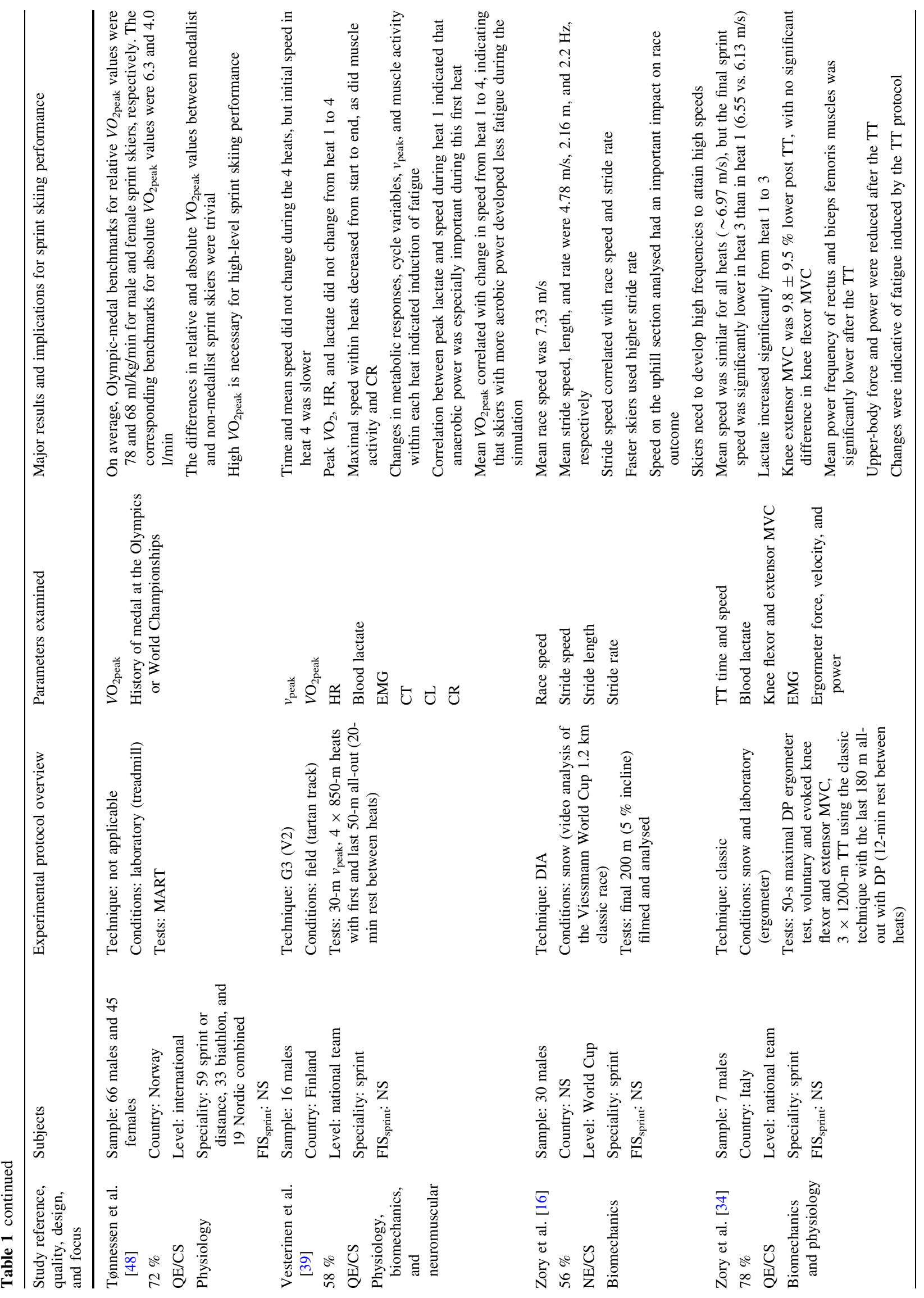




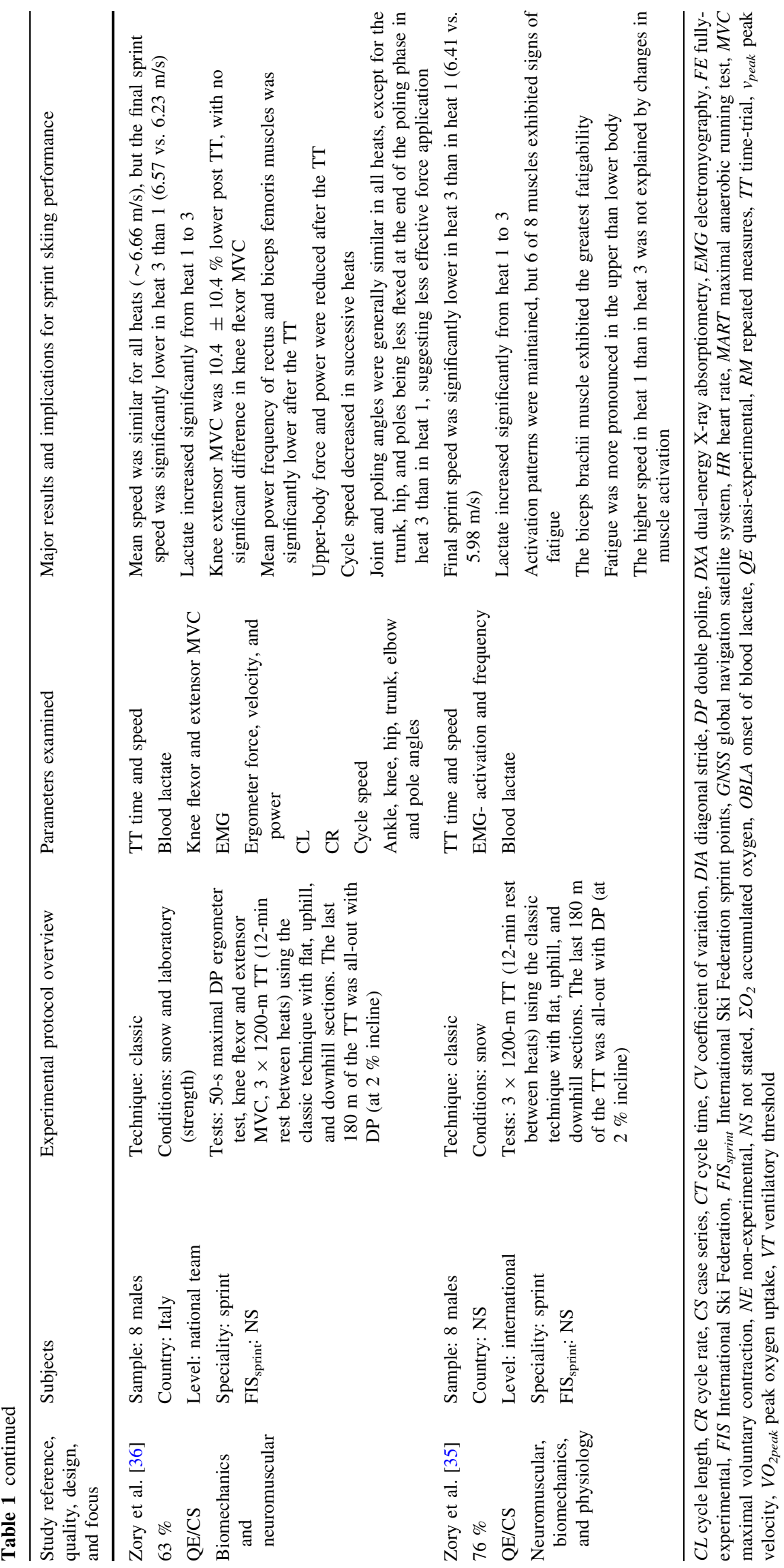


aerobic characteristics prevented fatigue accumulation during a simulation of a cross-country sprint skiing competition (four $850-\mathrm{m}$ repeated heats with 20 -min recovery between heats on roller-skis using the G3 (V2) skate technique), whereby individuals with greater mean $V \mathrm{O}_{2 \text { peak }}$ demonstrated smaller changes in mean velocities from heat 1 to 4 . However, it should be noted that although aerobic capacity was higher in world-class than national-level skiers [18], there was no meaningful difference in the relative and absolute $V \mathrm{O}_{2 \text { peak }}$ values of world-class skiers who won medals at the Olympics or World Championships and those who did not [48]. Anaerobic capacity is also a key indicator [11, 19, 29, 37-39], particularly with respect to performance during the first of repeated heats [39]. In addition, the more rapid reduction in blood levels of lactate in world-class sprint skiers following a single 4- to 6-min roller-skiing test to exhaustion on a treadmill using the G3 (V2) skate technique indicates that faster recovery might be beneficial in connection with the high-intensity repeated heats and limited recovery time characteristic of sprint skiing [18].

Among the biomechanical analyses carried out on a variety of techniques (see "Discipline" in Table 1), maximal speed [12-14, 17, 19, 29, 31, 33, 40-42, 44], cycle characteristics $[11-17,19,29,31,33,36,39-41,44,45]$, and kinetics (pole and plantar forces) [12, 14, 31, 32, $40,41,45]$ were the variables most often examined. Other biomechanical aspects addressed were joint angles [31, 32, 36, 41], electromyography [32, 34-36, 39], and performance measures using specialized ergometers or tests $[44,46]$.

In most cases, at top speed, the cycle length reached a plateau or even shortened [12, 33, 40], with increased speed across various techniques relying primarily on elevations in cycle rates $[12,16,33,40]$. In general, faster skiers demonstrated longer cycle lengths at peak, racing, and submaximal speeds [13, 17, 19, 33, 45]; longer swing (recovery) times [12, 33, 45]; better temporal coordination, including timing of the application of force [12, 45]; and greater effectiveness in transforming resultant pole and leg forces into propulsive ones [41].

Analysis of a single heat of a sprint race, both simulated and real, revealed that performance on the uphill sections exerted the greatest influence on race outcomes [15-17], with strong correlations between the time spent on these sections and the total heat time [15, 17]. Gear selection and transition are also important aspects, with faster skiers making fewer transitions during a single heat of a skating race and making greater use of the G3 (V2) than the G2 (V1) technique [15] since they could employ, for instance, G3 (V2) also when on steep inclines rather than reverting to G2 (V1). During $1100 \mathrm{~m}$ of classical sprint skiing, faster skiers were observed to employ fewer overall cycles of movement and fewer cycles of diagonal skiing, as well as tending to use the kick double poling technique more frequently [19].

Regarding anthropometry, the relative amount of lean mass has been associated with sprint double poling [14, 30, 38], diagonal stride [30], prologue race [47], and heat start [15] performances. More specifically, the absolute expression of lean mass in the whole, upper (arms and trunk), and lower body has been correlated with sprintprologue performance in one study [47]. However, in another study, the total body mass and trunk lean mass were positively related to both double poling and diagonal stride peak speed [30], with the upper and lower body lean masses only contributing to diagonal stride peak speed. Although certain researchers have reported a relationship between body mass $(\mathrm{kg})[30,38,43]$ and height [33] to selected measures of sprint skiing performance, others have found no such association $[15,30]$.

Several articles described upper-body power and strength as determinants of classic sprint performance in time-trials involving repeated heats and double poling peak speed on snow [34, 44], with skiers with greater double poling speeds producing a greater amount of upper-body power $[44,46]$. Measures of dynamic strength (e.g., squat jump height and bench press power) have also been related to varying extents to peak speed in connection with double poling, diagonal stride, and G3 (V2) technique [12, 38], as have maximal isometric trunk flexion and extension [38].

Fatigue has been examined using electromyography, speed profiles, biomechanical measures (e.g., poling forces, cycle characteristics, and fatigue indices), and physiological measures (e.g., lactate, heart rate, and $V_{2}$ ) in several studies in connection with classical sprint cross-country ski racing [14, 19, 34-36, 38], but only in one study in connection with skating [39]. In the latter investigation, muscle activity was attenuated at the end of each heat, although fatigue did not appear to accumulate across the four heats examined, which exhibited similar speed profiles [39]. In connection with sprint skiing using the classical technique, Zory and colleagues $[34,36]$ observed maintenance of mean speed in successive heats during a simulated race, although several parameters indicated fatigue, primarily of peripheral origin. For instance, lower- and upper-body force and power were impaired $[34,36]$, the mean power frequencies of electromyographic signals were reduced [34-36], and the twitch contractile properties of muscles were altered [34].

\section{Discussion}

Despite the relatively recent addition of sprint crosscountry skiing events to the Winter Olympic Games, 31 original research articles were found to investigate factors 
relating to performance in this sport at the time of this systematic review. Clearly, performance in sprint crosscountry skiing is complex and multi-factorial, as demonstrated by the large proportion of these articles that addressed physiological, biomechanical, anthropometric, and neuromuscular aspects simultaneously.

To summarize, adequate aerobic and anaerobic capacity are essential for successful sprint cross-country skiing. Although both systems play a role throughout the sprint competition, the anaerobic system may contribute more to the first of repeated heats and the aerobic system more to the subsequent heats $[38,39]$. Generation of high speed via an optimization of the interaction between cycle rate and length $[12,29,40]$ is of utmost importance [17-19, 28-30, 42]. Faster sprint skiers employ different strategies to approach maximal speeds, relying on technique [12, 33], movement efficiency [13, 17, 19, 33], and coordinated movement patterns and force application $[12,33]$. During races, performance on uphill sections exerts the greatest influence on the final outcome $[16,17]$ given that skiing speed decreases the most on steep uphill sections [15]. Hence, strong uphill performance is critical. Although a certain level of strength is required for successful sprint skiing, more does not necessarily appear to translate into superior sprint skiing performance $[12,18,29]$. Once the required strength level is reached, developing ski-specific power has the potential to influence performance to a greater extent, and can improve work efficiency, power output, and selected physiological parameters in well-trained skiers [51].

To elaborate, training strength and endurance capacities, particularly of the upper body, have the potential to reduce the negative impact of fatigue during sprint races involving a single or repeated heats [14, 34, 35], although leg [12, 40] and trunk [12, 30, 38] strength should clearly not be neglected. Heavy strength training is widely used by elite sprint skiers, and several studies have demonstrated correlations between measures of strength and various indicators of sprint skiing performance [12, 38, 46]. At the same time, beneficial effects of strength training interventions on sprint skiing performance are not always seen $[52,53]$. A recent intervention involving heavy strength training by junior female cross-country skiers (published after our systematic search) resulted in no significant effect on submaximal $\mathrm{O}_{2}$ cost during double poling or on average power output during maximal double-poling effort on an ergometer for 20-s or 3-min intervals [52]. Similarly, Losnegard et al. [53] observed no significant effect of heavy strength training on roller-skiing peak speed or single-heat time-trial performance by well-trained senior and junior Norwegian skiers.

The technical aspects of cross-country skiing are highly complex and, although increases in strength might improve sprint skiing performance, the timing of force application and the development of ski-specific power may exert a more pronounced influence than maximal strength per se [45, 51]. At the same time, it is important to note that in both studies cited above $[52,53]$, heavy strength training had no negative impact on the performance measures investigated, produced similar or even higher gains in these measures than traditional training, and was implemented for only 10-12 weeks, which might be insufficient for noticeable adaptation that influence skiing performance specifically. Furthermore, the effects of heavy strength training on performance during actual sprint competitions were not investigated.

Finally, available evidence regarding the impact of anthropometric characteristics on sprint skiing performance and peak speed is mixed; for instance, both beneficial [30, 33, 38, 43] and inconsequential [15, 30] effects of body height, mass, and body dimensions have been reported. However, more lean mass has been related to better outcomes during the first section of a single-heat time-trial performed on snow [15], during time-trials involving four $850-\mathrm{m}$ heats roller-skiing on a tartan track [38], and peak roller-skiing speed on a treadmill [30]; and, therefore, skiers should strive to optimize this particular anthropometric characteristic.

\subsection{Physiology}

One of the earliest publications in this field introduced a valid and reliable test concept for assessing sprint skiers, namely that of short-duration maximal double-poling roller-skiing efforts to predict double-poling sprint performance both in and outside of the laboratory [42]. Similar approaches were applied in several of the other studies included in this review [12, 13, 15, 18, 19, 30, 41, 45, 46], many highlighting that maximal speed over short distances $(20-50 \mathrm{~m})$ or relatively short durations ( $\sim 60$ to $90 \mathrm{~s})$ utilizing the various techniques [double poling, G3 (V2), and diagonal stride] correlated well with performance during time-trials involving single or repeated heats and/or FIS-sprint points [15, 18, 19]. Later, Sandbakk et al. [29] introduced a submaximal incremental roller-skiing test on a treadmill to quantify gross efficiency and aerobic/anaerobic metabolic rates, and an incremental time-to-exhaustion test to assess peak oxygen uptake in sprint skiers. More recently, the relative contribution of the aerobic and anaerobic energy systems to performance have been studied using ski-skating sprint time-trials at a self-selected pace first by Losnegard et al. [11], and more recently in the classical technique with junior cross-country skiers by McGawley et al. [54].

From the studies herein reviewed, the physiological factors observed to differ the most between sprint skiers of 
varying performance levels are aerobic capacity [17, 18, 38, 39, 49], anaerobic capacity [11, 19, 37-39], and skiing economy and efficiency [17, 18, 28, 29]. Many of these studies indicate that $V \mathrm{O}_{2 \text { peak }}$ exerts a significant impact on performance [17, 29, 37, 38, 43, 49], with higher $V \mathrm{O}_{\text {2peak }}$ (as assessed during roller-skiing on a treadmill) being associated with better FIS-point rankings [15], onsnow sprint skiing performance during a simulated prologue (classic and skate techniques) race [17, 43], and speed maintenance uphill during the later stages of a single-heat simulated sprint race using the skating technique [15, 17]. Carlsson et al. [43] suggested that sprint race performance improves by $0.2 \%$ for each $1 \%$ increase in absolute $V \mathrm{O}_{2 \text { peak }}$, although this simplified estimation does not account for all the factors that impact race performance. Furthermore, skiers with higher recorded $V \mathrm{O}_{2 \text { peak }}$ during a simulated sprint cross-country skate competition on a tartan track [using the G3 (V2) technique] were better able to maintain speed during four successive heats, indicating that aerobic power was especially important in the later heats [39]. However, it should be noted that once athletes reach a certain level of performance, such as competing in the Olympics or World Championships, higher aerobic capacity does not ensure a place on the winners' podium [48].

The anaerobic capacity of sprint skiers is also a key performance indicator [11, 19, 29, 37-39], with this system estimated to contribute $\sim 22$ to $26 \%$ of the total $\mathrm{O}_{2}$ demand during a $600-\mathrm{m}$ sprint skiing time-trial lasting $\sim 170$ to $190 \mathrm{~s}[11,54]$. In other words, the anaerobic system appears to contribute $\sim 25 \%$ of the total energy required during a sprint-skiing heat. However, during sections of a sprintskiing heat, the $\mathrm{O}_{2}$ demand can be much higher, implying an even greater anaerobic contribution [11, 17]. During maximal testing of anaerobic capacity using G3 (V2) involving four 850-m repeated heats on snow, faster sprint skiers have been shown to attain higher speeds [38], with world-class sprint skiers demonstrating greater gross efficiency and lower anaerobic metabolic rates at submaximal speeds compared to national-level sprint skiers using the same technique [18, 29]. Furthermore, sprint cross-country skiers are reported to have higher anaerobic capacities (i.e., greater accumulated oxygen deficits) than distance skiers [37], again suggesting the key role played by this capacity in elite sprint skiing. Other physiological characteristics related to indicators of sprint skiing performance include oxygen uptake at the lactate [43, 49] and ventilatory [49] thresholds.

It is worth noting here that the methods utilized to quantify the anaerobic contribution to sprint cross-country skiing differ. Earlier studies focused on increases in [17, 18] and peak [19] blood levels of lactate, whereas more recently the maximal accumulated oxygen deficit has been characterized [11, 37, 54-57]. Blood levels of lactate depend on the production, release, and utilization of this compound by active muscles. The arms of elite skiers are reported to release more lactate than they utilize during submaximal roller-skiing efforts with the classical technique, while the opposite situation has been observed in the legs [58]. Thus, the relative involvement of the arms and legs in cross-country skiing will exert a considerable influence on the blood levels of lactate, rendering the use of this measure to quantify the anaerobic capacity of skiers less valid.

Although no studies pertaining directly to recovery met inclusion for review here, an athlete's ability to recover is an aspect worth addressing in sprint cross-country skiing given the repeated-heat format of competitions $(4 \times 3$ - to 4-min efforts within a 2- to 3-h time span). Race analyses and practical observations of cross-country skiing competitions indicate that although some skiers are very good during the first half of the prologue, they cannot sustain their level of performance throughout the remainder of the competition (unpublished observation). Recently, a few studies have addressed the effects of varying recovery modes on repeated efforts in the context of sprint skiing $[55,59]$. Although active recovery was associated with a slightly, but significantly, greater effect on aerobic turnover than passive recovery [55], roller-skiing performance (two 800-m heats on a treadmill) using the G3 (V2) technique was similar. On the other hand, Stöggl and colleagues [59] observed that passive recovery resulted in greater decrements during high intensity runs to exhaustion compared to active recovery strategies implemented with or without supplementation. In combination, these two studies suggests a benefit of active versus passive recovery strategies during sprint skiing competitions, although further research is obviously needed to determine the optimal dosage and explore alternative recovery strategies.

The only fully-experimental study that met the criteria for inclusion in this review involved an 8-week intervention designed to reveal the effects of increased high-intensity endurance training (i.e., 2.5-fold increase in long duration high-intensity intervals performed at 85-92\% of peak heart rate) on sprint-skiing performance and aerobic characteristics of elite junior skiers [49]. The high-intensity endurance training positively impacted performance of a $1.5-\mathrm{km}$ time-trial $(\sim 3.5 \mathrm{~min})$ performed on roller skis outdoors in the skating technique, $V \mathrm{O}_{2 \text { peak }}$, and oxygen uptake at the ventilatory threshold [49]. Hence, a greater proportion of high-intensity endurance training on level terrain was recommended as a means of improving the performance of young athletes. However, it is difficult at this point to confirm whether such gains would also be achieved by senior athletes. The overall paucity of fullyexperimental studies included for review here reflects the 
inherent difficulties associated with studying high-level athletes and instigating interventions within their training programs. Training studies are time-consuming and require serial assessments and timely follow-ups [60].

\subsection{Biomechanics}

Studying cross-country skiing biomechanics is intricate given that the involvement of the upper and lower body differs across techniques and depends on terrain. For instance, the relative contribution of the upper body to propulsive forces during double poling is higher than with the other techniques. Across all techniques, high skiing speeds are reported to stem from an optimization of cycle rate and length [12, 29, 40]. Sandbakk et al. [29] observed that as skiing speed with the G3 (V2) technique increased to peak, skiers increased both cycle rate and length [29]. However, most researchers report a plateau or decrease in cycle length at maximal speeds $[12,33,40,61]$, with elevated speed relying primarily on more rapid cycle rates $[12,16,33,40,61]$. Nonetheless, skiers who demonstrated longer cycle lengths at given cycle rates outperformed those skiers with shorter cycles during both classic and skate skiing [12, 13, 17, 19, 33, 45]. The poling and swing time of the arms are also reported to decrease with increasing speed during G3 (V2), double poling, and diagonal stride [12, 33], with faster skiers employing longer swing times and spending a greater proportion of their cycle in the swing (recovery) than the thrust phase $[12,33,45]$.

In the case of sprint competitions in classical crosscountry skiing, top-ranked skiers have been observed to employ the double poling technique exclusively in all heats up to the finals when the track profile is appropriate [45]. With regards to double poling, biomechanical studies indicate that the duration of the preparation phase strongly relates to peak speed on flat terrain, with faster skiers exhibiting greater cycle lengths, longer swing and poling times, later and higher peak pole forces, and smaller poling angles with respect to the vertical direction at pole plant [45]. Noteworthy here is that the biomechanical and physiological aspects of double poling on uphill terrain at high skiing speeds were first investigated only recently, with double poling uphill being associated with much shorter swing times, as well as greater, later, and more effective pole forces than on flat terrain [62]. Within and between heats of a simulated sprint competition conducted on snow, fatigue was manifested by a decrease in double poling speeds [14, 36], increase in poling time [14], and decrease in poling force [14]. Stöggl and Müller [33] also observed more rapid cycle rates and shorter cycle times when double poling in a fatigued state at the end of a maximal anaerobic test, but no such changes when using the diagonal stride technique. Moreover, these investigators noted that absolute poling times employing these two classical techniques were maintained with fatigue, but that relative poling times became longer and swing times became shorter. Leg thrust times also increased with fatigue when utilizing the diagonal stride. In summary, faster sprint skiers appear to demonstrate greater maximal propulsive pole forces, as well as more resistance to, and better maintenance of, poling technique in connection with fatigue.

The techniques of cross-country skate skiing have evolved markedly over the years, with more explosive subtechniques being developed and utilized successfully for relatively short periods of time [7, 32]. For instance, although G2 (V1) has been shown to be faster than G3 (V2) on steep uphill inclines [31], on less steep inclines $\left(2^{\circ}\right.$ $10^{\circ}$ ), higher speeds can be reached using the double-push sub-technique of G3 (V2) [12, 31-33]. Higher-ranked skiers have also been observed to rely on the G3 (V2) technique on uphill sections of a single-heat time-trial simulation to a greater extent than those ranked lower. This difference is thought to reflect more frequent use of the double-push technique, higher uphill speed enabling use of a higher gear, and the superior upper-body strength and resilience to fatigue required for using G3 uphill exhibited by the better skiers [15]. That said, individual differences must always be taken into consideration since, at an individual level, certain athletes have been shown to achieve faster, slower, or comparable peak uphill speeds using the G2 (V1) compared to the double-push technique [31]. The double-push technique is very demanding (e.g., requires greater muscular activity of key muscles and plantar forces), which might restrict its use to short sections or for fast tactical accelerations during sprint events [32].

When approaching peak speed, faster skiers exhibit biomechanical strategies that differ from those of slower skiers [12, 32, 33, 45], not only in the magnitude of forces applied, but also with respect to their temporal coordination and instances of application [12]. For example, at peak G2 (V1) speed, faster skiers performed more synchronous pole plants, exhibited greater effectiveness in transforming resultant into propulsive forces, and used narrower edging angles [41]. They also generated greater propulsion at equal poling frequencies while employing the classic technique [19], and longer cycle lengths during G3 (V2) [13, 17, 29]. These findings agree with Holmberg et al. [63] who proposed more than a decade ago that faster skiers utilize a more sprinter-like double-poling technique, with higher peak poling forces and impulses, shorter relative poling times, and longer relative recovery times. Although contemporary double poling technique has evolved, these relationships are still evident during double poling on flat terrain [62]. Stöggl and colleagues [12] demonstrated that 
at maximal skiing speeds, the time for propulsion by the poles was $200 \mathrm{~ms}$ during double poling and G3 (V2), with as little as $150 \mathrm{~ms}$ for the leg push-off during diagonal stride [40]. These values are similar to the very short contact times associated with jumping exercises (e.g., the ground contact time during a drop jump), emphasizing the necessity for rapid production of force. At present, intervention studies concerning different techniques are lacking. Whether interventions aimed at modifying technical aspects can enhance the peak speed and sprint race performance of elite skiers remains to be determined scientifically.

\subsection{Neuromuscular Factors}

In cross-country skiing, the upper body plays a crucial role in overall performance $[34,44]$, and has been reported to contribute considerably to propulsion in several techniques [40, 41]. Custom-made ski-specific upper-body ergometers and assessment protocols have shown that faster skiers produce greater upper-body power [44, 46], indicating the significance of explosive upper-body strength. Furthermore, skiers with higher upper-body power and double poling peak speed have demonstrated less fatigue during a single-heat $1000-\mathrm{m}$ double poling sprint test [46]. Still, during simulated time-trials involving three 1200-m heats performed on snow, electromyography [34, 35] and kinetics [14] data have indicated greater upper body than lower body muscle fatigue [35]. Therefore, training the fatigue resistance of the upper body is also to be recommended and integrated into training programs of elite sprint skiers [14, 35].

The ability to develop large peak leg forces rapidly is also of fundamental importance to maximizing skiing speed (shown in particular for the diagonal stride) [12, 40], in agreement with previous cross-country skiing research not specifically addressing sprint skiing [64, 65]. Peak leg forces during diagonal stride on snow are reported to reach almost twice body mass and, at maximal speed, to be developed quite rapidly ( $\sim 100 \mathrm{~ms})$ [40]. Like sprint running [66], high forces (relative to the body mass of an individual) must be generated during short contact times and training of dynamic strength and motor skills designed to improve this ability could be beneficial to sprint skiers.

Previous studies have revealed that isometric upper- and lower-body strength do not correlate well with peak speed during the double poling, diagonal stride, and G3 (V2) techniques [12]; that dynamic strength (power output and vertical jump performance) correlates particularly well with peak speed during double poling and diagonal stride [12]; and that the 1-repetition maximal upper- and lowerbody strength of national- and international-level sprint skiers do not differ $[18,29]$. Overall, these findings indicate that: (1) elite skiers attain necessary levels of maximal strength beyond which further improvement does not necessarily enhance performance; (2) dynamic strength is a better indicator of performance than static strength and should be utilized in connection to training; and (3) repeated high-intensity efforts might be more suitable for assessing sprint-skiing abilities than a single maximal effort. There is also evidence that the trunk muscles contribute to the development of high speed [12, 30, 38], i.e., skiers with stronger [38] and leaner [30] trunks and who performed a greater number of brutal-bench repetitions [12] were also faster using the double poling, diagonal stride, and G3 (V2) techniques.

\subsection{Anthropometry}

Modifiable anthropometric characteristics, such as muscle mass and relative lean mass, have been related to the peak speed attained by elite cross-country skiers [30]. Lean mass in particular has been correlated with indicators of sprint performance (e.g., peak speed and single-heat time-trial) with both the classic and skating techniques [15, 30, 38, 47]. Absolute whole-, lower-, and upper-body lean mass (in $\mathrm{kg}$ ) show large to very large correlations with sprint-prologue performance in both men and women $(r=-0.66$ to $-0.82, p<0.05)$ [47]. Despite indications that total body mass $(\mathrm{kg})[30,38,43]$ and height [33] relate to sprint cross-country skiing performance, with elite sprint skiers reported to be being taller and heavier than distance skiers [17], other findings have found no such associations $[15,30]$. Perhaps more lean mass simply reflects greater muscle mass and strength, thereby corroborating earlier findings on cross-country skiing not related specifically to sprint events [67].

\subsection{Other Considerations}

The present review and articles included have several limitations. Given the array of experimental tasks and different types of skiers involved, it is challenging to generalize the findings from one study to another. In addition, although much focus has been placed here on studies that utilized peak speed as the performance outcome, this is only one of the parameters related to performance. As is the case with maximal strength, greater peak speed does not necessarily result in better sprint-skiing performance, especially when peak speed is determined over a very short distance [18]. Several other factors must also be considered.

FIS points are used to rank skiers internationally, but less than a third of the publications reviewed here reported FIS points [13, 17, 18, 29, 37, 40, 43, 47, 50] or attempted to correlate them with the investigated performance 
outcomes [15, 17, 18, 29, 37, 40, 43, 47, 50]. Also, sprint cross-country skiing competitions have evolved since their introduction to the World Cup circuit. Initially, four skiers competed head-to-head on a relatively flat course for $\sim 2$ min. Nowadays, six skiers compete against one another on a longer and hillier course, with races typically lasting $\sim 3 \mathrm{~min}$. These changes now enable endurance skiers to perform more successfully in sprint events also, particularly female skiers where sprint specialization is less evident [28].

Moreover, individual differences were noted in several of the articles reviewed [33, 35, 36]. As mentioned above, certain elite skiers showed faster, slower, or comparable peak speeds on uphill terrain using the G2 (V1) versus double-push technique [31]. Furthermore, individual responses to fatigue during a simulated classical sprint race were also observed in national skiers, with certain of these athletes decreasing both cycle length and rate or reducing only one of these two factors [36]. Pacing and tactical strategies have also been reported to differ between skiers and can impact race outcomes [15, 17], with most skiers seen to adopt a positive pacing strategy (i.e., athlete's speed progressively declines during the race [68]). More studies of individual responses to repeated heats, as well as of racing tactics associated with successful competition outcomes are required.

Factors associated with skiing performance with one technique or on one type of terrain do not necessarily exert an impact with other techniques or on different types of terrain. For instance, the factors associated with double poling performance on flat terrain are not the same as those associated with double-poling performance uphill [62]. The relative involvement of upper and lower body differ across techniques, where the propulsive forces are primarily developed from the upper body during double poling and from both the upper and lower body during the diagonal stride and skating techniques G2, G3, and G4 (V1, V2, and V2 alternate). Furthermore, although there are some indications that performance in the laboratory provides a valid indication of skiing performance on snow [13, 44], conclusions drawn from roller-skiing on a treadmill or on asphalt, paved roads, and tartan tracks might not always apply to on-snow skiing.

In addition, elite cross-country skiers and trainers should bear in mind that several factors other than those reviewed here, such as recovery [55] and nutritional strategies [69], may influence repeated sprint skiing performance. The muscle fibre composition or genetic make-up of elite sprint cross-country skiers has not yet been examined. These factors would be of considerable interest since: anaerobic performance has been related directly to the proportion of type II muscle fibres [70]; sprint runners are reported to exhibit a greater proportion of fast-twitch muscle fibres
[71]; and genetic factors have been shown to strongly influence the ability of skeletal muscles to produce explosive forces [72].

The age of peak cross-country sprint performance is another question yet to be addressed [73]. Work by Allen and Hopkins [73] indicates that for a sprint race of $\sim 3 \mathrm{~min}$ in duration, the optimal age is around $22.5 \mathrm{y}( \pm 1.3)$, but this needs to be confirmed for sprint skiers. Lastly, as in research on elite alpine ski racing [23], a relatively low number of female skiers were included in the studies reviewed here, which is of concern in light of the sex differences identified in elite sprint cross-country skiers with respect to physiology [13], biomechanics [13], anthropometry [47], degree of specialization [28], and factors predicting performance $[47,50]$. Clearly, further studies involving internationally competitive female sprint cross-country skiers are highly recommended, and such reports have now begun to appear more frequently since the date of our systematic search $[52,74,75]$. Fatigue and recovery during repeated heats tactics, and sex differences should be the focus of future studies in this field.

\section{Conclusions}

Cross-country skiing is demonstrably a demanding and complex sport. Successful sprint skiing requires numerous physiological, biomechanical, anthropometric, and neuromuscular attributes, including well-developed aerobic and anaerobic capacities, effective biomechanical techniques, a high proportion of lean mass, and the capability to generate high forces rapidly. The ability to attain high speed at the start of a sprint race, at any given point when required (e.g., when being challenged by a competitor), and in the final section of each heat, despite fatigue, is crucial to sprint skiing performance. A certain level of strength is also required, as well as the ability to tolerate fatigue during competitions and recover between heats. To expand our understanding of elite sprint skiing performance, future research should further investigate performance on snow, repeated-heat sprint performance, optimal recovery strategies, and the elite female skier, as well as factors not yet researched, such as muscle fibre constitution, genetic factors, nutrition/supplementation, and age of peak performance.

Acknowledgments The authors would like to thank the anonymous peer reviewers for their valuable feedback on this manuscript.

\section{Compliance with Ethical Standards}

Funding The authors acknowledge financial support from the Swedish Winter Sports Research Centre and the National Centre for Research in Sports (Centrum för idrottsforskning). 
Conflict of interest Kim Hébert-Losier, Christoph Zinner, Simon Platt, Thomas Stöggl and Hans-Christer Holmberg declare that they have no conflicts of interest relevant to the content of this review.

Open Access This article is distributed under the terms of the Creative Commons Attribution 4.0 International License (http:// creativecommons.org/licenses/by/4.0/), which permits unrestricted use, distribution, and reproduction in any medium, provided you give appropriate credit to the original author(s) and the source, provide a link to the Creative Commons license, and indicate if changes were made.

\section{References}

1. Smith GA. Biomechanical analysis of cross-country skiing techniques. Med Sci Sports Exerc. 1992;24(9):1015-22.

2. Smith GA. Biomechanics of crosscountry skiing. Sports Med. 1990;9(5):273-85.

3. Eisenman PA, Johnson SC, Bainbridge $\mathrm{CN}$, et al. Applied physiology of cross-country skiing. Sports Med. 1989;8(2): 67-79.

4. Hoffman MD, Clifford PS. Physiological aspects of competitive cross-country skiing. J Sports Sci. 1992;10(1):3-27.

5. Smith M, Matheson GO, Meeuwisse WH. Injuries in crosscountry skiing: a critical appraisal of the literature. Sports Med. 1996;21(3):239-50.

6. Morris PJ, Hoffman DF. Injuries in cross-country skiing. Trail markers for diagnosis and treatment. Postgrad Med. 1999;105(1):89-101.

7. Sandbakk $\varnothing$, Holmberg HC. A reappraisal of success factors for Olympic cross-country skiing. Int J Sports Physiol Perform. 2014;9(1):117-21.

8. Stöggl T, Stöggl R. Cross-country skiing in the 21 st centuryaltered demands and consequences for training in children and youths. In: Hakkarainen A, Linnamo V, Lindinger S, editors. 2nd International Congress on Science and Nordic Skiing, 28-31 May, 2012: Vuokatti, Finland; 2012. p. 73-85.

9. International Ski Federation. The International Ski Competition Rules (ICR). Oberhofen: International Ski Federation FIS; 2014. p. $1-85$.

10. Spencer M, Losnegard T, Hallén J, et al. Variability and predictability of performance times of elite cross-country skiers. Int $\mathbf{J}$ Sports Physiol Perform. 2014;9(1):5-11.

11. Losnegard T, Myklebust H, Hallén J. Anaerobic capacity as a determinant of performance in sprint skiing. Med Sci Sports Exerc. 2012;44(4):673-81.

12. Stöggl T, Müller E, Ainegren $M$, et al. General strength and kinetics: Fundamental to sprinting faster in cross country skiing? Scand J Med Sci Sports. 2011;21(6):791-803.

13. Sandbakk $\emptyset$, Ettema G, Leirdal S, et al. Gender differences in the physiological responses and kinematic behaviour of elite sprint cross-country skiers. Eur J Appl Physiol. 2012;112(3):1087-94.

14. Mikkola J, Laaksonen MS, Holmberg HC, et al. Changes in performance and poling kinetics during cross-country sprint skiing competition using the double-poling technique. Sports Biomech. 2013;12(4):355-64.

15. Andersson E, Supej M, Sandbakk $\varnothing$, et al. Analysis of sprint cross-country skiing using a differential global navigation satellite system. Eur J Appl Physiol. 2010;110(3):585-95.

16. Zory R, Barberis M, Rouard A. Kinematics of sprint crosscountry skiing. Acta Bioeng Biomech. 2005;7(2):87-96.

17. Sandbakk $\emptyset$, Ettema G, Leirdal S, et al. Analysis of a sprint ski race and associated laboratory determinants of world-class performance. Eur J Appl Physiol. 2011;111(6):947-57.
18. Sandbakk $\varnothing$, Holmberg HC, Leirdal S, et al. The physiology of world-class sprint skiers. Scand J Med Sci Sports. 2011;21(6):e9-16.

19. Stöggl T, Lindinger S, Müller E. Analysis of a simulated sprint competition in classical cross country skiing. Scand J Med Sci Sports. 2007;17(4):362-72.

20. Moher D, Liberati A, Tetzlaff J, et al. Preferred reporting items for systematic reviews and meta-analyses: the PRISMA statement. Ann Intern Med. 2009;4:264-9.

21. Downs SH, Black N. The feasibility of creating a checklist for the assessment of the methodological quality both of randomised and non-randomised studies of health care interventions. J Epidemiol Community Health. 1998;52(6):377-84.

22. Costa MJ, Bragada JA, Marinho DA, et al. Longitudinal interventions in elite swimming: a systematic review based on energetics, biomechanics, and performance. J Strength Cond Res. 2012;26(7):2006-16.

23. Hébert-Losier K, Supej M, Holmberg HC. Biomechanical factors influencing the performance of elite alpine ski racers. Sports Med. 2014;44(4):519-33.

24. Andrew E, Anis A, Chalmers T, et al. A proposal for structured reporting of randomized controlled trials. JAMA. 1994;272(24): 1926-31.

25. Hurley WL, Denegar CR, Hertel J. Research methods: a framework for evidence-based clinical practice. Baltimore: Lippincott Williams \& Wilkins; 2011. p. 89-107, 124-38.

26. Berg KE, Latin RW. Essentials of research methods in health, physical education, exercise science, and recreation. 3rd ed. Baltimore: Lippincott Williams \& Wilkins; 2008. p. 216-44.

27. Rowell LB. Human cardiovascular adjustments to exercise and thermal stress. Physiol Rev. 1974;54(1):75-159.

28. Sandbakk $\varnothing$, Ettema G, Holmberg HC. Gender differences in endurance performance by elite cross-country skiers are influenced by the contribution from poling. Scand J Med Sci Sports. 2014;24(1):28-33.

29. Sandbakk $\varnothing$, Holmberg HC, Leirdal S, et al. Metabolic rate and gross efficiency at high work rates in world class and national level sprint skiers. Eur J Appl Physiol. 2010;109(3):473-81.

30. Stöggl T, Enqvist J, Müller E, et al. Relationships between body composition, body dimensions, and peak speed in cross-country sprint skiing. J Sports Sci. 2010;28(2):161-9.

31. Stöggl T, Kampel W, Müller E, et al. Double-push skating versus V2 and V1 skating on uphill terrain in cross-country skiing. Med Sci Sports Exerc. 2010;42(1):187-96.

32. Stöggl T, Müller E, Lindinger S. Biomechanical comparison of the double-push technique and the conventional skate skiing technique in cross-country sprint skiing. J Sports Sci. 2008;26(11):1225-33.

33. Stöggl T, Müller E. Kinematic determinants and physiological response of cross-country skiing at maximal speed. Med Sci Sports Exerc. 2009;41(7):1476-87.

34. Zory R, Millet G, Schena F, et al. Fatigue induced by a crosscountry skiing KO sprint. Med Sci Sports Exerc. 2006;38(12):2144-50.

35. Zory R, Molinari F, Knaflitz M, et al. Muscle fatigue during cross country sprint assessed by activation patterns and electromyographic signals time-frequency analysis. Scand J Med Sci Sports. 2011;21(6):783-90.

36. Zory R, Vuillerme N, Pellegrini B, et al. Effect of fatigue on double pole kinematics in sprint cross-country skiing. Hum Mov Sci. 2009;28(1):85-98.

37. Losnegard T, Hallén J. Physiological differences between sprintand distance-specialized cross-country skiers. Int J Sports Physiol Perform. 2014;9(1):25-31.

38. Mikkola J, Laaksonen M, Holmberg HC, et al. Determinants of a simulated cross-country skiing sprint competition using V2 
skating technique on roller skis. J Strength Cond Res. 2010;24(4):920-8.

39. Vesterinen V, Mikkola J, Nummela A, et al. Fatigue in a simulated cross-country skiing sprint competition. J Sports Sci. 2009;27(10):1069-77.

40. Andersson E, Pellegrini B, Sandbakk $\varnothing$, et al. The effects of skiing velocity on mechanical aspects of diagonal cross-country skiing. Sports Biomech. 2014;13(3):267-84.

41. Stöggl T, Holmberg HC. Three-dimensional force and kinematic interactions in V1 skating at high speeds. Med Sci Sports Exerc. 2015;47(6):1232-42.

42. Stöggl T, Lindinger S, Müller E. Reliability and validity of test concepts for the cross-country skiing sprint. Med Sci Sports Exerc. 2006;38(3):586-91.

43. Carlsson M, Carlsson T, Knutsson M, et al. Oxygen uptake at different intensities and sub-techniques predicts sprint performance in elite male cross-country skiers. Eur J Appl Physiol. 2014;114(12):2587-95.

44. Bortolan L, Pellegrini B, Finizia G, et al. Assessment of the reliability of a custom built Nordic Ski Ergometer for crosscountry skiing power test. J Sports Med Phys Fit. 2008;48(2):177-82.

45. Stöggl T, Holmberg HC. Force interaction and 3D pole movement in double poling. Scand J Med Sci Sports. 2011;21(6):393-404.

46. Stöggl T, Lindinger S, Müller E. Evaluation of an upper-body strength test for the cross-country skiing sprint. Med Sci Sports Exerc. 2007;39(7):1160-9.

47. Carlsson M, Carlsson T, Hammarström D, et al. Prediction of race performance of elite cross-country skiers by lean mass. Int J Sports Physiol Perform. 2014;9(6):1040-5.

48. Tønnessen E, Haugen TA, Hem E, et al. Maximal aerobic capacity in the winter-Olympics endurance disciplines: Olympicmedal benchmarks for the time period 1990-2013. Int J Sports Physiol Perform. 2015;10(7):835-9.

49. Sandbakk $\varnothing$, Welde B, Holmberg HC. Endurance training and sprint performance in elite junior cross-country skiers. J Strength Cond Res. 2011;25(5):1299-305.

50. Carlsson M, Carlsson T, Hammarström D, et al. Time trials predict the competitive performance capacity of junior crosscountry skiers. Int J Sports Physiol Perform. 2014;9(1):12-8.

51. Nilsson JE, Holmberg HC, Tveit P, et al. Effects of 20-s and 180 -s double poling interval training in cross-country skiers. Eur J Appl Physiol. 2004;92(1-2):121-7.

52. Skattebo Ø, Hallén J, Rønnestad BR, et al. Upper body heavy strength training does not affect performance in junior female cross-country skiers. Scand J Med Sci Sports. 2015;. doi:10.1111/ sms.12517.

53. Losnegard T, Mikkelsen K, Ronnestad BR, et al. The effect of heavy strength training on muscle mass and physical performance in elite cross country skiers. Scand J Med Sci Sports. 2011;21(3):389-401.

54. McGawley K, Holmberg HC. Aerobic and anaerobic contributions to energy production among junior male and female crosscountry skiers during diagonal skiing. Int J Sports Physiol Perform. 2014;9(1):32-40.

55. Losnegard T, Andersen M, Spencer M, et al. Effects of active versus passive recovery in sprint cross-country skiing. Int J Sports Physiol Perform. 2015;10(5):630-5.

56. Andersson E, Bjorklund G, Holmberg HC, et al. Energy system contributions and determinants of performance in sprint cross- country skiing. Scand J Med Sci Sports. 2016;. doi:10.1111/sms. 12666.

57. Sandbakk $\varnothing$, Hegge AM, Losnegard T, et al. The physiological capacity of the world's highest ranked female cross-country skiers. Med Sci Sports Exerc. 2016;. doi:10.1249/MSS.0000000 000000862.

58. Van Hall G, Jensen-Urstad M, Rosdahl H, et al. Leg and arm lactate and substrate kinetics during exercise. Am J Physiol Endocrinol Metab. 2003;284(1):E193-205.

59. Stöggl T, Torres-Peralta R, Cetin E, et al. Repeated high intensity bouts with long recovery: are bicarbonate or carbohydrate supplements an option? Sci World J. 2014;2014(145747):1-8.

60. Stöggl TL, Sperlich B. The intensity distribution among welltrained and elite endurance athletes. Front Physiol. 2015;6(295): $1-14$.

61. Lindinger SJ, Stoggl T, Müller E, et al. Control of speed during the double poling technique performed by elite cross-country skiers. Med Sci Sports Exerc. 2009;41(1):210-20.

62. Stöggl T, Holmberg HC. Double-poling biomechanics of elite cross-country skiers: flat versus uphill terrain. Med Sci Sports Exerc. 2016;. doi:10.1249/mss.0000000000000943.

63. Holmberg HC, Lindinger S, Stöggl T, et al. Biomechanical analysis of double poling in elite cross-country skiers. Med Sci Sports Exerc. 2005;37(5):807-18.

64. Nilsson J, Tveit P, Eikrehagen O. Cross-country skiing. Sports Biomech. 2004;3(1):85-108.

65. Vähäsöyrinki P, Komi PV, Seppälä S, et al. Effect of skiing speed on ski and pole forces in cross-country skiing. Med Sci Sports Exerc. 2008;40(6):1111-6.

66. Weyand PG, Sternlight DB, Bellizzi MJ, et al. Faster top running speeds are achieved with greater ground forces not more rapid leg movements. J Appl Physiol. 2000;89(5):1991-9.

67. Larsson P, Henriksson-Larsen K. Body composition and performance in cross-country skiing. Int J Sports Med. 2008;29(12): 971-5.

68. Abbiss CR, Laursen PB. Describing and understanding pacing strategies during athletic competition. Sports Med. 2008;38(3): 239-52.

69. Beaven CM, Maulder P, Pooley A, et al. Effects of caffeine and carbohydrate mouth rinses on repeated sprint performance. Appl Physiol Nutr Metab. 2013;38(6):633-7.

70. Esbjörnsson M, Sylven C, Holm I, et al. Fast twitch fibres may predict anaerobic performance in both females and males. Int $\mathrm{J}$ Sports Med. 1993;14(5):257-63.

71. Costill DL, Daniels J, Evans W, et al. Skeletal muscle enzymes and fiber composition in male and female track athletes. J Appl Physiol. 1976;40(2):149-54.

72. Eynon N, Hanson ED, Lucia A, et al. Genes for elite power and sprint performance: ACTN3 leads the way. Sports Med. 2013;43(9):803-17.

73. Allen SV, Hopkins WG. Age of peak competitive performance of elite athletes: a systematic review. Sports Med. 2015;45(10): 1431-41.

74. Born DP, Faiss R, Willis SJ, et al. Circadian variation of salivary immunoglobin A, alpha-amylase activity and mood in response to repeated double-poling sprints in hypoxia. Eur J Appl Physiol. 2016;116(1):1-10.

75. Carlsson M, Carlsson T, Wedholm L, et al. The physiological demands of competitive sprint and distance performance in elite female cross-country skiing. J Strength Cond Res. 2016; doi:10. 1519/jsc.0000000000001327. 